Published in final edited form as:

Nat Immunol. 2021 June 01; 22(6): 746-756. doi:10.1038/s41590-021-00940-2.

\title{
Metabolic Reprogramming of Terminally Exhausted CD8+ $T$ cells by IL-10 Enhances Anti-Tumor Immunity
}

\author{
Yugang Guo ${ }^{\# 1,2}$, Yu-Qing Xie ${ }^{\# 1}$, Min Gao', Yang Zhao1, Fabien Franco ${ }^{3,4}$, Mathias Wenes ${ }^{3}$, \\ Imran Siddiqui ${ }^{3}$, Alessio Bevilacqua ${ }^{3,4}$, Haiping Wang ${ }^{3,4}$, Hanshuo Yang ${ }^{5}$, Bing Feng ${ }^{1,2}$, Xin \\ $\mathrm{Xie}^{6}$, Catherine M. Sabatel ${ }^{3}$, Benjamin Tschumi ${ }^{3}$, Amphun Chaiboonchoe $^{7}$, Yuxi Wang ${ }^{8}$, \\ Weimin $\mathrm{Li}^{8}$, Weihua Xiao ${ }^{9}$, Werner Held ${ }^{3}$, Pedro Romero ${ }^{3}$, Ping-Chih $\mathrm{Ho}^{3,4,{ }^{*}}$, Li Tang ${ }^{1,2,{ }^{*}}$ \\ ${ }^{1}$ Institute of Bioengineering, École Polytechnique Fédérale de Lausanne (EPFL), 1015 Lausanne, \\ Switzerland ${ }^{2}$ Institute of Materials Science \& Engineering, EPFL, 1015 Lausanne, Switzerland \\ ${ }^{3}$ Department of Oncology, University of Lausanne, 1066 Epalinges, Switzerland ${ }^{4}$ Ludwig Institute \\ for Cancer Research, University of Lausanne, 1066 Epalinges, Switzerland ${ }^{5}$ State Key Laboratory \\ of Biotherapy and Cancer Center, West China Hospital, Sichuan University and Collaborative \\ Innovation Center of Biotherapy, 610041 Chengdu, China ${ }^{6} \mathrm{Center}$ for Genomics and Systems \\ Biology, New York University Abu Dhabi, 129188 Abu Dhabi, United Arab Emirates ${ }^{7}$ Siriraj Center \\ of Research Excellence for Systems Pharmacology, Department of Pharmacology, Faculty of \\ Medicine, Siriraj Hospital, Mahidol University, 10700 Bangkok, Thailand ${ }^{8}$ Department of \\ Respiratory and Critical Care Medicine, West China Medical School/West China Hospital, \\ Sichuan University, 610041 Chengdu, China ${ }^{9}$ Hefei National Laboratory for Physical Sciences at \\ Microscale, The CAS Key Laboratory of Innate Immunity and Chronic Disease, Department of \\ Oncology of the First Affiliated Hospital, Division of Life Sciences and Medicine, University of \\ Science and Technology of China, 230026 Hefei, China \\ \# These authors contributed equally to this work.
}

\begin{abstract}
T cell exhaustion presents one of the major hurdles to cancer immunotherapy. Among exhausted $\mathrm{CD} 8^{+}$tumor-infiltrating lymphocytes (TILs), the terminally exhausted subset contributes directly to tumor cell killing owing to its cytotoxic effector function. However, this subset does not respond to immune checkpoint blockades and is difficult to be reinvigorated with restored proliferative capacity. Here, we show that a half-life-extended interleukin (IL)-10/Fc fusion protein directly
\end{abstract}

Users may view, print, copy, and download text and data-mine the content in such documents, for the purposes of academic research, subject always to the full Conditions of use: http://www.nature.com/authors/editorial_policies/license.html\#terms

*e-mail: li.tang@epfl.ch, ping-chih.ho@unil.ch.

Author contributions

Y.G., Y.-Q.X., and L.T. conceived the study. Y.G., Y.-Q.X., L.T. and P.-C.H. designed the experiments. Y.G., Y.-Q.X., M.G., Y.Z., F.F., M.W., I.S., A.B., H.W., H.Y., B.F., X.X., C.M.S., B.T., A.C., Y.W., W.L., W.X., W.H., and P.R. performed the experiments. Y.G., Y.-

Q.X., L.T. and P.-C.H. analyzed the data. Y.G., Y.-Q.X., and L.T. wrote the manuscript. All authors edited the manuscript.

Competing interests

Y.G., L.T., and Y.-Q.X. are inventors on patents (International Publication Number WO 2021053134) related to the technology described in this manuscript. The remaining authors declare no competing interests.

Reporting summary

Further information on research design is available in the Nature Research Reporting Summary linked to this paper. 
and potently enhanced expansion and effector function of terminally exhausted CD8 ${ }^{+}$TILs by promoting oxidative phosphorylation (OXPHOS), a process independent of the progenitor exhausted T cells. IL-10/Fc was a safe and highly efficient metabolic intervention that synergized with adoptive $\mathrm{T}$ cell transfer immunotherapy, leading to eradication of established solid tumors and durable cures in a majority of treated mice. These findings show that metabolic reprogramming by upregulating mitochondrial pyruvate carrier-dependent OXPHOS can revitalize terminally exhausted $\mathrm{T}$ cells and enhance the response to cancer immunotherapy.

Cancer immunotherapy represented by immune checkpoint blockades (ICBs) has achieved remarkable clinical success ${ }^{1}$. However, an outstanding challenge remains that a great majority of patients fail to respond to this therapy ${ }^{2-4}$. The low response rate is in part due to the fact that tumor infiltrating lymphocytes (TILs) become exhausted and eventually incapable to control tumor progression ${ }^{5-7}$. Two distinct subsets of exhausted CD8 $8^{+}$TILs are recently identified with different functional properties ${ }^{8-11}$. One of the subsets, termed 'progenitor exhausted' (TCF-1 $\left.1^{+} \mathrm{TIM}-3^{-}\right) \mathrm{CD} 8^{+} \mathrm{T}$ cells, shows relatively high proliferative capacity and the capability to differentiate into 'terminally exhausted' (TCF-1-TIM- $3^{+}$) CD8 ${ }^{+}$TILs, the other subpopulation that directly contributes to the killing of tumor cells owing to its superior cytotoxicity to the progenitor exhausted TILs. Progenitor exhausted $\mathrm{CD} 8^{+} \mathrm{T}$ cells can respond to anti-PD- 1 checkpoint blockade therapy and mediate tumor growth control ${ }^{8-10}$. However, terminally exhausted CD8 ${ }^{+}$TILs, a subset with impaired proliferative capacity, do not respond to ICBs or most existing immunotherapies ${ }^{8,12-14}$ Therefore, it remains a significant challenge to reinvigorate the terminally exhausted subpopulation of $\mathrm{CD} 8^{+}$TILs in the tumor microenvironment (TME) and exploit its therapeutic potential.

Metabolic restriction imposed in the TME, such as glucose deprivation and hypoxia, greatly alters the cell signaling of TILs leading to impaired anti-tumor immune responses ${ }^{15,16}$. It has been reported that exhausted $\mathrm{T}$ cells exhibit suppressed mitochondrial respiration and/or glycolysis and such poor metabolic fitness may reinforce $\mathrm{T}$ cell exhaustion ${ }^{17-20}$. Metabolic interventions that could enhance the effector function and proliferative capacity of exhausted $\mathrm{T}$ cells are thereby being actively pursued. We and others have shown that maintaining mitochondrial fitness restores the proliferation and effector function of exhausted $\mathrm{T}$ cells leading to enhanced anti-tumor immunity ${ }^{18-20}$. Interleukin-10 (IL-10) is a pleiotropic cytokine that can promote anti-tumor immunity in multiple murine tumor models ${ }^{21-23}$. Recently, patients treated with PEGylated IL-10 (pegilodecakin) showed increased number of PD- 1 and LAG-3 positive CD8 ${ }^{+} \mathrm{T}$ cells in the circulation ${ }^{24}$. In addition, IL-10 has been shown to enhance the mitochondrial oxidative phosphorylation (OXPHOS) of macrophages ${ }^{25}$. However, whether IL-10 could also reprogram $\mathrm{T}$ cell metabolic profiles and restore the function of exhausted $\mathrm{T}$ cells remains unexplored.

Here, we report that a half-life-extended interleukin (IL)-10/Fc fusion protein directly expanded terminally exhausted CD $8^{+}$TILs and promoted their effector function in a way independent of progenitor exhausted $\mathrm{CD}^{+}$TILs, leading to eradication of established solid tumors and durable cures in a majority of treated mice when combined with adoptive $\mathrm{T}$ cell transfer (ACT) or ICB immunotherapy. Our results provide preclinical evidence that 
IL-10/Fc is a safe and highly effective therapy that acts on a specific subset of CD8 ${ }^{+}$TILs distinct from those responding to ICBs. Thus, IL-10/Fc could potentially complement and synergize with many existing cancer immunotherapies for enhanced efficacy and response rates. Furthermore, we found that IL-10/Fc reprogramed T cell metabolism by promoting OXPHOS through the mitochondrial pyruvate carrier (MPC) and such metabolic reprogramming was essential for reactivating terminally exhausted CD8 ${ }^{+}$TILs and enhancing the ultimate therapeutic outcome by IL-10/Fc. These findings provide new insight into the crucial role of metabolic profiles in $\mathrm{T}$ cell exhaustion and reinvigoration and lay the foundation for further identification of metabolic switches for regulating $\mathrm{T}$ cell activities in the TME.

\section{Results}

\section{IL-10/Fc reinvigorates terminally exhausted CD8+ ${ }^{+}$ILs}

We first produced a recombinant half-life-extended fusion protein of human IL-10 and IgG1 Fc (IL-10/Fc), which could cross-react with mouse IL-10 receptor (IL-10R) ${ }^{26}$ in a dosedependent manner (Extended Data Fig. 1a-d). To treat subcutaneous (s.c.) B16F10 tumors, we transferred PMEL CD $8^{+} \mathrm{T}$ cells $\left(5 \times 10^{6}\right)$ that recognize the gp100 cognate antigen to mice through intravenous (i.v.) injection adjuvanted by peritumorally (p.t.) administered IL-10/Fc or phosphate-buffered saline (PBS) as control. B16F10 melanoma is a poorly immunogenic tumor with very few lymphocyte infiltrates ${ }^{27,28}$. ACT of tumor antigenspecific PMEL CD8 ${ }^{+} \mathrm{T}$ cells greatly enhanced tumor infiltration of total CD45.2 $2^{+}$TILs and $\mathrm{CD}^{+} \mathrm{T}$ cells (Extended Data Fig. 1e,f) providing the basis for us to assess the effects of IL-10/Fc on exhausted TILs. We found that the treatment of IL-10/Fc combined with ACT markedly increased the number of $\mathrm{CD}^{+}$TILs, particularly, $\mathrm{CD}^{+} \mathrm{T}$ cells, as compared to ACT alone (Fig. 1a). Interestingly, IL-10/Fc treatment induced no significant alteration in counts or inflammatory properties of other lymphocytes or myeloid cells in the TME except that inhibition of dendritic cell (DC) maturation was noticed (Extended Data Fig. 1g-i).

We next determined the specific subset(s) of CD8 ${ }^{+}$TILs that responded to IL-10/Fc treatment. Among all the $\mathrm{CD} 8^{+} \mathrm{TILs}$, terminally exhausted $\mathrm{CD} 8^{+} \mathrm{T}$ cells were substantially expanded, whereas the frequencies and counts of progenitor exhausted $\mathrm{CD} 8^{+} \mathrm{T}$ cells (TCF- $1^{+}$TIM- $3^{-}$) remained unchanged or slightly decreased (Extended Data Fig. 2a-c). We noticed that the TCF-1 ${ }^{-}$TIM- $3^{+}$subpopulation was completely in line with the PD- $1^{+}$TIM- $3^{+}$double positive subset (Fig. 1b), which also showed reduced polyfunctionality (Extended Data Fig. 2d). Such observation was consistent with that in chronic infections ${ }^{12-14}$. To simplify the staining procedures and analyses, we next used surface inhibitory markers, PD-1 and TIM-3, to define the terminally exhausted subpopulation in the following experiments. IL-10/Fc treatment markedly and selectively expanded the PD $-1^{+}$TIM $-3^{+}$double positive but not the PD- $1^{+}$single positive subset, with substantially increased frequencies as well as 10.5- and 3.3-fold greater cell counts (combination treatment vs. ACT alone) of adoptively transferred PMEL and endogenous CD8 ${ }^{+} \mathrm{T}$ cells, respectively (Fig. 1c,d). The PD- $1^{+}$TIM- $3^{+}$T cells also exhibited enhanced BrdU incorporation and Ki67 expression when treated with $\mathrm{IL}-10 / \mathrm{Fc}$, suggesting increased proliferative capacity (Fig. 1e). 
Consistently, we observed the highest expression level of IL-10R subunit alpha (IL-10Ra) on the PD- $1^{+} \mathrm{TIM}-3^{+} \mathrm{CD} 8^{+} \mathrm{T}$ cells among all the subsets of $\mathrm{CD} 8^{+}$TILs (Fig. 2a). In addition, IL-10Ra knock out (KO) P14 CD8 ${ }^{+} \mathrm{T}$ cells failed to respond to IL-10/Fc treatment for cell expansion in vitro and in vivo (Fig. 2b; Extended Data Fig. 2e-g), suggesting IL-10/Fc signals directly through IL-10R on T cells. Importantly, the expanded PD- $1^{+} \mathrm{TIM}-3^{+} \mathrm{CD} 8^{+}$ TILs retained their superior capacity in producing granzyme $\mathrm{B}$, a key cytotoxic molecule, and other effector molecules (Fig. 2c,d), and showed higher expression level of activation marker CD69 (Fig. 2e) as well as reduced expression of inhibitory marker PD-1 (Fig. 2f), a phenotype that was also observed in $T o x$-mutant exhausted $\mathrm{CD} 8^{+} \mathrm{T}$ cells ${ }^{29}$. Altogether, IL-10/Fc promoted proliferation and effector function of terminally exhausted CD8 ${ }^{+}$TILs through IL-10R on T cells.

\section{IL-10/Fc directly expands terminally exhausted CD8+ TILs}

Notably, the expansion of PD- $1^{+}$TIM- $3^{+}$double positive CD8 ${ }^{+}$TILs by IL-10/Fc was antigen-dependent. In a co-transfer experiment, PMEL and OT-I (T cell receptor (TCR) transgenic $\mathrm{T}$ cells recognizing ovalbumin (OVA) antigen) $\mathrm{CD}^{+} \mathrm{T}$ cells were coadministered in mice bearing B16F10 tumors (Fig. 3a). The frequency of PD- $1^{+} \mathrm{TIM}^{+} 3^{+}$ double positive cells and total transferred cells of PMEL but not OT-1 T cells were significantly increased by IL-10/Fc (Fig. 3b-d). The results suggest that only the antigenspecific (PMEL) terminally exhausted CD8 ${ }^{+}$TILs respond to IL-10/Fc treatment. To examine whether terminally exhausted $\mathrm{T}$ cells responded to IL-10/Fc treatment directly, we next transferred the two subsets (PD- $1^{+}$TIM- $3^{-}$and PD- $1^{+}$TIM- $3^{+}$) of PMEL $\mathrm{T}$ cells sorted from $\mathrm{CD}^{+}$TILs to recipient mice bearing $\mathrm{B} 16 \mathrm{~F} 10$ tumors. We found the PD- $1^{+}$TIM- $3^{+} \mathrm{CD}^{+}$T cells were markedly expanded in vivo in the absence of PD- $1^{+} \mathrm{TIM}-3^{-}$ CD8 ${ }^{+}$T cells (Extended Data Fig. 3a,b). Ex vivo culture of the two sorted subsets separately confirmed that the increased PD- ${ }^{+} \mathrm{TIM}-3^{+}$population upon IL-10/Fc treatment was contributed mainly by direct expansion of the terminally exhausted $\mathrm{T}$ cells rather than the conversion from progenitor exhausted T cells (Extended Data Fig. 3c-f). In addition, the treatment of IL-10/Fc showed negligible effect on the apoptosis of CD8 ${ }^{+}$TILs indicating the increase counts of PD- $1^{+} \mathrm{TIM}-3^{+} \mathrm{CD} 8^{+} \mathrm{T}$ cells was not due to reduced cell apoptosis either (Extended Data Fig. 3g).

To confirm the above findings, we next exploited $T_{c f} 7^{\text {DTR-GFP }}$ transgenic P14 T cells that allow a selective depletion of the progenitors $\left(\mathrm{TCF}^{-} 1^{+}\right)$by diphtheria toxin (DT) treatment ${ }^{9}$. With the progenitors depleted in vivo (Extended Data Fig. 3h,i), the terminally exhausted subset $\left(T_{c f} 7^{\text {DTR-GFP- }}\right.$ PD- $1^{+}$TIM- $\left.3^{+} \mathrm{CD}^{+}\right)$in tumor still responded to the IL-10/Fc treatment and was expanded to a comparable level as that in mice without DT depletion suggesting the expansion of terminally exhausted T cells by IL-10/Fc treatment is independent of the progenitors (Fig. 3e,f). To determine the direct contribution of terminally exhausted T cells in tumor growth control, we transferred $T_{c f}{ }^{\text {DTR-GFP }}$ transgenic P14 T cells recognizing gp33 antigen to mice bearing B16-gp33 tumors (Fig. 3g,h). With DT mediated depletion of the progenitor exhausted T cells, the combination therapy of ACT and IL-10/Fc induced similar tumor regression and curative responses to that without depletion implying the terminally exhausted $\mathrm{T}$ cells responded directly to IL-10/Fc for enhanced anti- 
tumor efficacy. Therefore, IL-10/Fc expanded the antigen-specific terminally exhausted $\mathrm{CD}^{+}$TILs in a progenitor exhausted cell-independent manner.

\section{IL-10/Fc promotes OXPHOS of T cells}

Inspired by the observation that IL-10 reprograms the metabolic profiles of macrophages ${ }^{25}$, we next examined whether IL-10/IL-10R signaling regulates $\mathrm{CD} 8^{+} \mathrm{T}$ cell metabolism in order to elucidate the underlying mechanism. Upon TCR stimulation with peptide-pulsed antigen presenting cells or a dimerized anti-CD3 antibody, both naïve and primed $\mathrm{CD} 8^{+} \mathrm{T}$ cells upregulated OXPHOS in the presence of IL-10/Fc evidenced by higher basal oxygen consumption rates (OCR) (Fig. 4a,b). To mimic the persistent tumor-antigen stimulation in the TME, we set up a co-culture system of B16F10 mouse melanoma cells and activated PMEL CD ${ }^{+} \mathrm{T}$ cells. Both basal and maximal OCR of $\mathrm{CD} 8^{+} \mathrm{T}$ cells were elevated markedly upon IL-10/Fc treatment whereas extracellular acidification rate (ECAR) remained stable (Fig. 4c,d; Extended Data Fig. 4a,b). The ratios of OCR to ECAR were also significantly increased (Fig. 4e). These results suggest that IL-10/Fc actively reprograms $\mathrm{T}$ cell metabolism toward higher OXPHOS dependence when there is persistent antigen stimulation. Such antigen dependence for metabolic reprogramming was consistent with the observed antigen-dependent $\mathrm{CD}^{+} \mathrm{TIL}$ expansion in vivo. Furthermore, the T cell proliferation was greatly enhanced by IL-10/Fc, so was the killing efficiency against B16F10 target cells in the co-culture experiment (Fig. 4f,g), providing evidence that the promoted OXPHOS may lead to enhanced proliferative capacity and cytotoxicity of $\mathrm{CD} 8^{+} \mathrm{T}$ cells.

To recapitulate the terminal exhaustion phenotype in vivo, we next produced PD- $1^{+}$TIM $-3^{+} \mathrm{CD}^{+}$T cells ex vivo through over stimulation with a dimerized anti-CD3 antibody (Extended Data Fig. 5a). Sorted subpopulation of PD- $1^{+} \mathrm{TIM}-3^{+} \mathrm{CD} 8^{+} \mathrm{T}$ cells with a good number could hence be obtained, which had been confirmed with the TCF-1-TIM-3 ${ }^{+}$ phenotype (Extended Data Fig. 5b). Ex vivo produced and sorted PMEL PD- $1^{+}$TIM $-3^{+} \mathrm{CD} 8^{+} \mathrm{T}$ cells showed similarly elevated levels of OCR and ratio of OCR to ECAR as the whole $\mathrm{CD} 8^{+} \mathrm{T}$ cell population (Fig. $4 \mathrm{~h}-\mathrm{j}$ ), and were markedly expanded by IL-10/Fc (Fig. 4k). Using IL-10Ra-KO CD8 ${ }^{+} \mathrm{T}$ cells over stimulated by the dimerized antiCD3 antibody we found the metabolic reprogramming of T cells by IL-10/Fc was indeed dependent on IL-10R on T cells (Fig. 4l,m).

To extend this observation to human T cells, we co-cultured human chimeric antigen receptor (CAR)-T cells that targeted human epidermal growth factor receptor 2 (HER2) with ME275 human melanoma cells expressing HER2 (ME275-HER2) or HER2 positive SKOV3 human ovarian cancer cells (SKOV3-HER2). We found human CAR-T cells responded to IL-10/Fc treatment similarly as mouse $\mathrm{T}$ cells exhibiting enhanced OCR, proliferation, and killing efficiency against target cells (Extended Data Fig. 6a-c). Human PD- $1^{+} \mathrm{LAG}-3^{+} \mathrm{CD} 8^{+}$ $T$ cells induced by over stimulation of an anti-human CD3 antibody expressed the highest level of IL-10Ra among all the subsets of $\mathrm{CD}^{+} \mathrm{T}$ cells and responded to IL-10/Fc treatment in a similar way (Extended Data Fig. 6d-f). Altogether, IL-10/Fc promoted OXPHOS of mouse and human $\mathrm{T}$ cells leading to enhanced proliferative capacity and cytotoxicity. 


\section{IL-10/Fc potentiates ACT and ICB immunotherapies}

The discovery that IL-10/Fc expands the terminally exhausted CD8 ${ }^{+}$TILs while promoting their effector function motivated us to assess the anti-solid tumor efficacy of ACT immunotherapies in combination with IL-10/Fc. In a therapeutic setting with B16F10 tumor, a poorly immunogenic and highly aggressive mouse melanoma model, the combination therapy of p.t. administered IL-10/Fc and adoptive transfer of activated PMEL CD8 ${ }^{+} \mathrm{T}$ cells $\left(5 \times 10^{6}\right)$ without lympho-depletion preconditioning consistently induced complete tumor regression and durable cures in $90 \%$ of treated mice (Fig. 5a,b; Extended Data Fig. 7a). In contrast, ACT treatment alone transiently controlled tumor growth but failed to induce tumor regression. Administration of IL-10/Fc in the absence of ACT eradicated 30\% of tumors suggesting the need of exogenous tumor-reactive $T$ cells to achieve superior efficacy. In line with the potent anti-tumor efficacy, combination therapy of ACT and IL-10/Fc induced remarkably high ratio of $\mathrm{CD} 8^{+} \mathrm{T}$ cells to regulatory $\mathrm{T}\left(\mathrm{T}_{\text {reg }}\right)$ cells and high frequency of cytotoxic and polyfunctional cells among both endogenous and transferred $\mathrm{CD} 8^{+} \mathrm{T}$ cells (Extended Data Fig. 7b,c). Furthermore, close to $80 \%$ of long-term survivors treated with IL-10/Fc plus ACT rejected a rechallenge of B16F10 cells two months post cessation of therapy, indicating the induction of anti-tumor immune memory (Fig. 5c). Notably, IL-10/Fc administration with even 50\% lower dosing frequency led to similar anti-tumor efficacy with $80 \%$ of B16F10 tumors cleared when combined with ACT (Extended Data Fig. 7d-h).

To test the robustness of this combination therapy, we next assessed whether large established solid tumors could be controlled. OVA-expressing YUMM1.7 mouse melanoma cells (YUMM1.7-OVA) were inoculated s.c. and allowed to grow to high tumor burden (size $\geq 50 \mathrm{~mm}^{2}$ or $\left.150 \mathrm{~mm}^{3}\right)^{30,31}$ before the initiation of therapy. Combined treatment of ACT of OT-I CD $8^{+} \mathrm{T}$ cells $\left(5 \times 10^{6}\right)$ and IL-10/Fc led to remarkable tumor regression and eventually elimination, while ACT alone showed only transient tumor growth inhibition without durable therapeutic effect (Fig. 5d). In addition, more than $60 \%$ of mice treated with IL-10/Fc and ACT combination therapy exhibited long-term survival and $100 \%$ of the survivors rejected a rechallenge of YUMM1.7-OVA cells (Fig. 5e,f). We next extended this combination strategy to CAR-T cell therapy, which is an important immunotherapy modality in the clinic ${ }^{32}$. We prepared mouse CAR-T cells that targeted HER2 and inoculated mice with MC38-HER2 tumor, a murine colon adenocarcinoma stably transfected with HER2. Transfer of HER2-targeting CAR-T cells $\left(5 \times 10^{6}\right)$ alone to mice resulted in minimum therapeutic effect (Fig. 5g,h). By contrast, ACT of CAR-T cells adjuvanted by IL-10/Fc completely eradicated tumors and led to durable cures in $\sim 90 \%$ of treated mice. Notably, $100 \%$ of the cured animals that rejected primary tumors after CAR-T cells and IL-10/Fc combination therapy also rejected a second challenge of MC38-HER2 cells (Fig. 5i). Lymphoreplete models were used in all the ACT therapeutic studies above-mentioned permitting the harnessing of the host anti-tumor immunity, and overcoming the need for preconditioning, a procedure that is typically necessary for ACT therapy in the clinic but excludes many patients due to life-threatening toxicities ${ }^{33}$. Importantly, unlike other immune stimulatory cytokines, such as IL-2 ${ }^{34}$ or IL- $15^{35}$, IL-10/Fc treatment alone or in combination with ACT was safe and exhibited no overt toxicities. All the treated mice showed no body weight loss or elevation of serum levels of liver enzymes (Extended Data Fig. 7i-k). In addition, we found the combination of IL-10/Fc and anti-PD-1 eradicated established tumors 
and induced durable immune protection in a mouse CT26 colorectal tumor model (Extended Data Fig. 8). Thus, IL-10/Fc markedly and safely enhanced ACT and ICB immunotherapies leading to robust and complete responses and durable cures in a majority of mice with established solid tumors.

\section{IL-10/Fc enhances OXPHOS of terminally exhausted CD8+ ${ }^{+}$TILs}

In order to understand how IL-10/Fc treatment regulates the gene expression of terminally exhausted CD8 $8^{+}$TILs in vivo, we performed an RNA-sequencing (RNA-seq) analysis of sorted tumor antigen-specific Thy $1.1^{+} \mathrm{PD}-1^{+} \mathrm{TIM}-3^{+} \mathrm{CD} 8^{+}$TILs from B16F10 tumors treated with ACT in combination with IL-10/Fc or PBS control (Fig. 6a). IL-10/Fc treatment led to significant changes in 842 genes (adjusted $P$ values $<0.05$ ) in the PD- $1^{+}$TIM- $3^{+}$ subpopulation of $\mathrm{CD}^{+} \mathrm{T}$ cells in tumors (Fig. 6b; Extended Data Fig. 9a,b). The PD- $1^{+}$TIM- $3^{+} \mathrm{CD} 8{ }^{+}$TILs in the IL-10/Fc treated group showed higher expression of genes encoding complexes for electron transport chain (ETC) that is OXPHOS related ${ }^{36}$, including Atp6v1g1, Cox5a, Cox8a, Ndufa5 and Ndufv3, as well as those encoding cytotoxic molecules including Gzmb, Klra2, Klrc2, $N \mathrm{~kg} 7$ and Tnfsf10, but lower expression of genes encoding inhibitory receptors and exhaustion transcription factors such as Cd200r1 and $\mathrm{Nr}_{4} \mathrm{a} 2$ compared to control cells (Fig. 6c). The results were consistent with the observed phenotypes of IL-10/Fc-treated PD- $1^{+} \mathrm{TIM}-3^{+} \mathrm{CD} 8^{+}$TILs and their metabolic profiles in vitro. In addition, gene set enrichment analysis (GSEA) and ingenuity pathway analysis (IPA) of the transcriptional differences between IL-10/Fc and PBS control groups revealed strong enrichment of gene signatures and pathways associated with T cell OXPHOS and effector function (Fig. 6d,e; Extended Data Fig. 9c,d).

To further characterize the metabolic regulation effect of IL-10/Fc in vivo, we analyzed the mitochondrial profiles of $\mathrm{CD}^{+}$TILs. In agreement with the RNA-seq data, we found IL-10/Fc treatment upregulated the levels of mitochondrial reactive oxygen species (ROS) in the PD- $1^{+}$TIM $-3^{+} \mathrm{CD}^{+}$TILs indicating enhanced mitochondrial respiration in vivo (Fig. 6f). In order to directly measure the metabolic profile of sorted CD8 $8^{+}$TILs, we were able to isolate PD- $1^{+}$TIM- $3^{+} \mathrm{CD} 8^{+}$TILs of a high enough count from YUMM1.7-OVA tumors. Consistent with the RNA-seq data and in vitro results, IL-10/Fc treatment markedly increased the basal OCR level of the PD- $1^{+}$TIM- $3^{+} \mathrm{CD} 8^{+}$TILs (Fig. $6 \mathrm{~g}$ ). These results indicated that terminally exhausted $\mathrm{CD} 8^{+}$TILs underwent metabolic reprograming toward OXPHOS, remained highly cytotoxic, and maintained effector function following exposure to IL-10/Fc.

\section{IL-10/Fc promotes OXPHOS in a MPC-dependent manner}

We next used several pathway-specific inhibitors to probe the molecular basis of metabolic regulation of T cells by IL-10/Fc (Fig. 7a-c). Surprisingly, the enhanced OXPHOS was not a result from increased activity of fatty acid oxidation (FAO) or glutaminolysis as the treatment with FAO inhibitor etomoxir (ETO) and glutaminase inhibitor Bis-2-(5phenylacetamido-1,3,4-thiadiazol-2-yl)ethyl sulphide (BPTES) did not impair the IL-10/Fcinduced elevation of OXPHOS or $\mathrm{CD}^{+} \mathrm{T}$ cell proliferation. However, inhibiting glycolysis with 2-Deoxy-D-glucose (2DG) or blocking pyruvate transportation by inhibiting MPC with UK5099 completely abrogated the effect of IL-10/Fc. Given that MPC plays a central role 
on importing cytosolic pyruvate into the mitochondrial matrix ${ }^{37}$, our results suggest IL-10/Fc-induced metabolic regulation might rely on pyruvate generated from glycolysis. To further examine this postulate, we crossed the $M p c 1$-floxed mice $\left(M p c 1^{f l / f 1}\right)^{38,39}$ with $C d 4^{c r e} \times$ OT-I transgenic mice in order to obtain the MPC1 deficient OT-I mice, in which $M p c 1$ gene was ablated in OT-I T cells. Compared to wild-type OT-I CD8 ${ }^{+} \mathrm{T}$ cells, MPC 1KO OT-I CD8 ${ }^{+} \mathrm{T}$ cells failed to respond to IL-10/Fc for promoting OXPHOS or cell expansion (Fig. 7d,e). In addition, the mitochondrial biomass, membrane potential, and ROS level of the wild-type, but not MPC1-KO, PD- $1^{+} \mathrm{TIM}-3^{+} \mathrm{CD} 8^{+}$OT-I TILs in the B16F10OVA tumors were increased upon IL-10/Fc treatment (Extended Data Fig. 10a-c), indicating that IL-10/Fc enhanced the mitochondrial function of terminally exhausted CD8 ${ }^{+}$TILs in a pyruvate/MPC-dependent manner. Interestingly, we found the IL-10/Fc treatment showed minimum effect on either protein expression or RNA transcription level of MPC1 in $\mathrm{CD} 8^{+} \mathrm{T}$ cells (Extended Data Fig. 10d, e). Indeed, re-stimulated CD8 ${ }^{+} \mathrm{T}$ cells upon IL-10/Fc treatment resulted in activation of STAT3 signaling (Extended Data Fig. 10f), which may interact with ETC complexes in mitochondria and boost ETC activities for enhanced $\mathrm{OXPHOS}^{40}$. Altogether, IL-10/Fc promoted OXPHOS and mitochondrial function in T cells in a MPC-dependent manner.

\section{Metabolic reprogramming is essential for $\mathrm{T}$ cell reinvigoration}

It is worth noting that the effect of IL- $10 / \mathrm{Fc}$ on enhancing proliferation and cytotoxicity (represented by granzyme B production) of the PD- $1^{+} \mathrm{TIM}-3^{+} \mathrm{CD} 8^{+} \mathrm{T}$ cells was abrogated by the treatment of oligomycin, an OXPHOS pan inhibitor ${ }^{41}$ (Fig. 7c,f), suggesting the induced metabolic reprogramming was necessary for reinvigorating terminally exhausted $\mathrm{T}$ cells by IL-10/Fc. Directly feeding wild-type OT-I CD8 ${ }^{+} \mathrm{T}$ cells, but not MPC1-KO OT-I $\mathrm{CD} 8^{+} \mathrm{T}$ cells, with sodium pyruvate as an alternative approach of metabolic reprogramming to the IL-10/Fc treatment similarly promoted the proliferation of PD- $1^{+} \mathrm{TIM}-3^{+} \mathrm{CD} 8^{+} \mathrm{T}$ cells upon restimulation by dimerized anti-CD3 antibody (Fig. $7 \mathrm{~g}, \mathrm{~h}$ ), providing additional evidence that metabolic reprogramming could be an underlying mechanism for reinvigorating exhausted T cells.

To confirm that pyruvate/MPC-dependent OXPHOS is essential for in vivo expansion of terminally exhausted $\mathrm{CD} 8^{+}$TILs and ultimate therapeutic outcome, we next transferred MPC1-KO OT-I CD8 ${ }^{+} \mathrm{T}$ cells or wild-type OT-I CD8 ${ }^{+} \mathrm{T}$ cells to mice bearing s.c. B16F10OVA tumors in combination with IL-10/Fc or PBS control treatment. IL-10/Fc treatment failed to expand the total $\mathrm{CD} 8^{+}$TILs or the PD- $1^{+} \mathrm{TIM}-3^{+}$subpopulation in mice receiving adoptive transfer of MPC1-KO OT-I CD8 ${ }^{+} \mathrm{T}$ cells as compared to that of wild-type OT-I $\mathrm{CD} 8^{+} \mathrm{T}$ cells (Fig. 7i,j). We next assessed the therapeutic efficacy of ACT therapy of MPC1KO OT-I CD $8^{+} \mathrm{T}$ cells combined with IL-10/Fc in YUMM1.7-OVA tumor-bearing mice. The combination of adoptively transferred MPC1-KO OT-I CD8 ${ }^{+} \mathrm{T}$ cells and IL-10/Fc exhibited significantly reduced efficacy in tumor growth control compared to that of wildtype OT-I CD8 ${ }^{+} \mathrm{T}$ cells and IL-10/Fc, suggesting that promoting MPC-dependent OXPHOS was necessary for the enhanced therapeutic efficacy mediated by IL-10/Fc (Fig. 7k). These results indicated that MPC-dependent metabolic reprogramming was essential for revitalizing the terminally exhausted CD8 ${ }^{+}$TILs by IL-10/Fc. 


\section{Discussion}

T cell exhaustion is one of the major barriers to an effective cancer immunotherapy ${ }^{5,6}$. While intratumoral progenitor exhausted T cells are known to respond to ICBs, terminally exhausted $\mathrm{CD} 8^{+} \mathrm{T}$ cells are currently believed to be difficult to be reactivated with most existing immunotherapies. Here, we demonstrated IL-10/Fc was a safe and highly efficient metabolic intervention that directly expanded terminally exhausted CD8 ${ }^{+}$TILs and enhanced their cytotoxic functions leading to curative cancer immunotherapies. Furthermore, we showed that IL-10/Fc promoted the pyruvate and MPC-dependent OXPHOS of $\mathrm{T}$ cells inducing reinvigoration of terminally exhausted $\mathrm{T}$ cells for enhanced anti-tumor immunity.

We found the therapeutic mode of IL-10/Fc was distinct from and complementary to that of ICBs. The effect of anti-PD-1 antibody therapy relies on the progenitor exhausted CD8 ${ }^{+}$ TILs (PD- $1^{+} \mathrm{TCF}-1^{+} \mathrm{TIM}^{-} 3^{-}$) in the TME ${ }^{8,14}$. Anti-PD- 1 antibody therapy induces the proliferation and differentiation of progenitor exhausted CD8 ${ }^{+}$TILs, which subsequently lead to the expansion of terminally exhausted $\mathrm{CD} 8^{+}$TILs exerting the cytotoxic function against cancer cells. In contrast, the therapeutic effect of IL-10/Fc is independent of progenitor exhausted $\mathrm{CD} 8^{+}$TILs. Although possessing superior cytotoxic function to the progenitor cells, terminally exhausted $\mathrm{CD} 8^{+}$TILs are short-lived and incapable of selfrenewing. To the best of our knowledge, IL-10/Fc is the first reported cytokine therapy that directly expands the terminally exhausted $\mathrm{CD} 8^{+}$TILs in the absence of the progenitor cells. We have examined the sources and found the increased terminally exhausted $\mathrm{T}$ cells upon the IL-10/Fc treatment were contributed mainly by the direct expansion of terminally exhausted CD8 ${ }^{+}$TILs (IL-10R-dependent) rather than the conversion from progenitor exhausted $\mathrm{T}$ cells or the reduced apoptosis of terminally exhausted $\mathrm{T}$ cells. The therapeutic outcome and duration of response to ICB therapy may be limited in patients with poor/none tumor infiltration of progenitor exhausted CD $8^{+}$TILs. Therefore, the treatment of IL-10/Fc provides a complementary strategy to the existing immunotherapies for enhancing patients' response rate.

Metabolically fit effector $\mathrm{T}$ cells undergo a metabolic switch to relying on aerobic glycolysis upon activation to meet the high energetic and biosynthesis demands for proliferation and effector function ${ }^{42-44}$. By contrast, exhausted $\mathrm{T}$ cells exhibit significant metabolic depression of glycolysis and/or OXPHOS ${ }^{17}$. In particular, impaired mitochondrial OXPHOS was recently found to drive $\mathrm{T}$ cell exhaustion ${ }^{18-20}$. CD $8^{+}$TILs under persistent antigen stimulation and metabolic stress accumulated dysfunctional mitochondria leading to reduced proliferative capacity and effector function ${ }^{18-20}$. In line with these observations, our results also imply that terminally exhausted T cells may undergo metabolic adaption in TME to reduce pyruvate-dependent OXPHOS. By directly feeding terminally exhausted T cells with sodium pyruvate to rewire $\mathrm{T}$ cell metabolism instead of using $\mathrm{IL}-10 / \mathrm{Fc}$, we showed that elevated pyruvate-dependent OXPHOS was indeed sufficient to promote the proliferation of wild-type T cells but not the MPC1-KO T cells. Furthermore, the necessity of promoted OXPHOS for enhanced proliferation and effector function of terminally exhausted $\mathrm{T}$ cells as well as the ultimate therapeutic efficacy induced by IL-10/Fc treatment was confirmed by a set of experiments using an OXPHOS inhibitor (oligomycin) or MPC1-KO T cells, where 
the effects of IL-10/Fc were completely abrogated. Together, these observations implicate that elevation of pyruvate and MPC-dependent OXPHOS is sufficient and necessary for revitalization of terminally exhausted $\mathrm{CD}^{+} \mathrm{T}$ cells by IL-10/Fc. This finding lays the foundation for further identification of metabolic stimulations that are needed for reinvigorating terminally exhausted $\mathrm{T}$ cells, currently a major limitation for cancer immunotherapy.

Substrates for mitochondrial OXPHOS include pyruvate, fatty acids, and glutamine. Intriguingly, we found that the enhancement of pyruvate and MPC-dependent OXPHOS rather than FAO or glutaminolysis was necessary for restoring the functionality of terminally exhausted CD8 ${ }^{+} \mathrm{T}$ cells by IL-10/Fc. Our discovery suggests that the effect of metabolic reprograming on anti-tumor immunity of $\mathrm{T}$ cells might be pathway and source specific. However, it remains elusive how IL-10/Fc boosts pyruvate and MPC-dependent OXPHOS in terminally exhausted T cells. Several other pathways related to T cell functions, such as CD28 signaling and NFAT, were also found to be significantly upregulated by IL-10/Fc in the IPA analysis. Elucidating the role of metabolic reprogramming and related signaling pathways in regulating the differentiation, exhaustion, and function of various immune cells, such as T cells and natural killer cells, will likely provide critical insight into the design of next-generation immunotherapy enabled by metabolic interventions. Besides cancer, one may expect IL-10/Fc shows similar effects on the terminally exhausted T cells in chronic infections.

Combination cancer immunotherapy involving IL-10/Fc was safe and highly effective. Treatment of solid tumors with ACT immunotherapy remains a major challenge and cures are typically rare. When combined with ACT therapy, IL-10/Fc eradicated a majority of established solid tumors leading to durable cures and protection in multiple mouse tumor models. IL-10/Fc based metabolic therapy should be applicable in combinations with many existing immunotherapies for enhanced efficacy, such as ICBs, cancer vaccines, and so on. TILs from patients who fail to respond to ICBs may be dominated by the terminally exhausted subpopulation ${ }^{8,14}$. Therefore, the combination of IL-10/Fc with anti-PD-1 therapy could potentially improve patients' response rate. Indeed, some preclinical ${ }^{45}$ and clinical ${ }^{46}$ evidence has been reported recently showing improved therapeutic outcome of such combination. Furthermore, IL-10/Fc similarly promoted OXPHOS and proliferation of human T cells.

Importantly, IL-10/Fc selectively expanded the tumor antigen-specific CD8 ${ }^{+}$TILs but not the bystander $\mathrm{CD} 8^{+} \mathrm{T}$ cells showing good safety profiles, which were confirmed by the measurements of body weight and serum levels of liver enzymes of treated mice. A recent Phase I clinical trial shows encouraging results that combination of a PEGylated IL-10 with an anti-PD-1 monoclonal antibody was relatively safe and activated the anti-tumor immunity in patients with advanced solid tumors ${ }^{46}$, indicating the high translational potential of such combinations in the clinic. 


\section{Methods}

\section{Mice}

Six to eight-week old female CD45.2 $2^{+}$Thy $1.2^{+}$C57BL/6 (C57BL/6J) mice, BALB/c (BALB/cByJ) mice, and CD45.1 mice (B6.SJL-Ptprc ${ }^{a} P e p c^{b} /$ BoyCrl) were purchased from Charles River Laboratories. T cell receptor (TCR)-transgenic Thy $1.1^{+}$pmel-1 (PMEL) mice (B6.Cg-Thy ${ }^{a} / \mathrm{Cy} \mathrm{Tg(TcraTcrb)8Rest/J)} \mathrm{and} \mathrm{TCR-transgenic} \mathrm{OT-I} \mathrm{mice} \mathrm{(C57BL/6-}$ $\operatorname{Tg}(\mathrm{TcraTcrb}) 1100 \mathrm{Mjb} / \mathrm{J})$ were originally purchased from The Jackson Laboratory and maintained in EPFL Center of PhenoGenomics (CPG) animal facility. Transgenic mice that carried CD4 promoter-mediated Cre recombinase ( $\mathrm{Cd}^{c r e}$ mice, (B6.Cg- $\mathrm{Tg}(\mathrm{Cd} 4-\mathrm{cre}) 1 \mathrm{Cwi} /$ BfluJ)), TCR-transgenic P14 mice (B6;D2-Tg(TcrLCMV)327Sdz/JDvsJ), Rosa26-LSLCas9 knock in mice ${ }^{47}$ (B6J.129(B6N)-Gt(ROSA)26Sor tm1(CAG-cas 9*-EGFP)Fezh/J )and

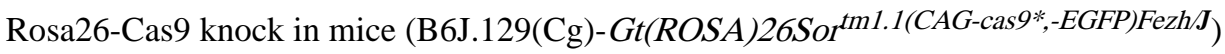
were originally purchased from the Jackson Laboratory and maintained at the University of Lausanne's pathogen-free facility. CRISPR-Cas9 knock in P14 TCR transgenic mice were obtained by crossing of Rosa26-LSL-Cas9 knock in mice with $C d 4^{c r e}$ mice on a P14 background. CD45.1 mice were crossed with CD45.2 ${ }^{+}$C57BL/6 mice to generate CD45. $1^{+}$CD $45.2^{+}$mice. CRISPR-Cas9 knock in P14 TCR transgenic mice were crossed with CD45.1 mice to generate CRISPR-Cas9 knock in P14 TCR transgenic mice on either CD 45. $1^{+}$background or CD45. $1^{+}$CD $45.2^{+}$background. Thy $1.1^{+}$PMEL mice were crossed with Thy $1.2^{+}$C57BL/6 mice to generate Thy $1.2^{+}$PMEL mice. OT-I mice were crossed with

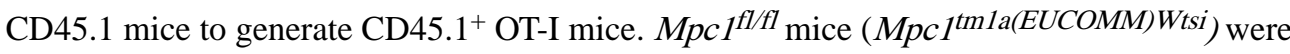
obtained from J.-C. Martinou (University of Geneva) with permission from J. Rutter (University of Utah School of Medicine) ${ }^{48}$. Mpc $1^{f l / f l}$ mice were crossed to $C d 4^{c r e}$ mice on an OT-I background to generate MPC1 knock out (MPC1-KO) OT-I mice. $T c f 7^{\text {DTR-GFP }}$ P14 mice on a CD45.2 background were generated as described ${ }^{9}$. The genotyping was confirmed by Transnetyx. All mice were housed in EPFL Center of PhenoGenomics or conventional animal facility of University of Lausanne and were kept in individually ventilated cages, between $19-23{ }^{\circ} \mathrm{C}$ with $45-65 \%$ humidity and with a 12 hour dark/light cycle. Experimental procedures in mouse studies were approved by the Swiss authorities (Canton of Vaud, animal protocol ID 3206, 3533, 3009, 2688.2 and 3040.1) and performed in accordance with the guidelines from CPG of EPFL and the animal facility of University of Lausanne.

\section{Human blood samples}

All human blood samples (prepared as buffy coats) were purchased from Interregional Blood Transfusion SRC Ltd. with informed consent of anonymous healthy donors, and genetically engineered with ethics approval from the Federal Office of Public Health OFSP, Switzerland (Notification 4182209/2).

\section{Cells and tumor models}

B16F10 melanoma cell, CT26 mouse colorectal cancer cell, human epidermal growth factor receptor 2 (HER2) positive SKOV3 human ovarian cancer cell (SKOV3-HER2), HEK293T and Phoenix-Eco cell were originally acquired from the American Type Culture Collection. B16-gp33, B16F10-OVA, and YUMM1.7-OVA mouse melanoma cell lines were generated as previously reported ${ }^{9,49}$. HER2 transduced MC38 mouse colon cancer cell line (MC38- 
HER2) and ME275 human melanoma cell line (ME275-HER2) were generated according to the previous publication ${ }^{50}$. All the mouse tumor cells and SKOV3-HER2 cells were cultured in complete Dulbecco's modified Eagle's medium (DMEM), a DMEM (Gibco / Thermo Fisher Scientific) medium supplemented with fetal bovine serum (FBS) (10\% v/v, Gibco / Thermo Fisher Scientific) and penicillin/streptomycin (1\% v/v, Gibco / Thermo Fisher Scientific). ME275-HER2 human melanoma cells were cultured in RPMI-1640 (Gibco / Thermo Fisher Scientific) medium supplemented with FBS (10\% v/v, Gibco / Thermo Fisher Scientific), HEPES (pH 7.2 7.5, 1\% v/v, Gibco / Thermo Fisher Scientific), penicillin/streptomycin (1\% v/v, Gibco / Thermo Fisher Scientific). B16F10, YUMM1.7OVA, B16F10-OVA, B16-gp33, or MC38-HER2 tumor cells $\left(5 \times 10^{5}\right.$ or $1 \times 10^{6}$ or as indicated) were implanted subcutaneously (s.c.) into the right flanks of Thy $1.2^{+}$C57BL/6 wild-type (WT) mice to establish the syngeneic tumor models. CT26 mouse colorectal cancer cells $\left(3 \times 10^{5}\right)$ were s.c. inoculated into the right flanks of BALB/c mice.

\section{Production of IL-10/Fc protein}

As reported previously ${ }^{51-53}$, the IL-10/Fc fusion protein containing a human IL-10 fused at the N-terminal with a noncytolytic human IgG1 Fc was expressed by FreeStyle 293-F Cells (Gibco / Thermo Fisher Scientific) at the EPFL Protein Expression Core Facility. Supernatant of culture medium containing IL-10/Fc fusion protein was harvested by centrifugation after a 7 -day culture and was filtered through a $0.22-\mu \mathrm{m}$ membrane to obtain a clear solution. The recombinant protein was first captured with a HiTrap Protein A affinity chromatography column on an AKTA pure 25 (GE Healthcare), and eluted with an elution buffer (0.05-M sodium citrate, $0.3-\mathrm{M}$ sodium chloride, $\mathrm{pH}=3.0)$. The eluted protein was collected immediately in a neutralization buffer $(1-\mathrm{M}$ Tris-HCl, $\mathrm{pH}=10.0)$ followed by concentration with membrane ultrafiltration (molecular weight cut-off $10 \mathrm{kDa}$ ) in a Vivaspin (GE Healthcare). The concentrated protein solution was further purified with a Superdex 200 increase size exclusion chromatography (GE Healthcare) at a flow rate of $1.0 \mathrm{~mL} / \mathrm{min}$ with phosphate buffered saline (PBS) buffer on AKTA pure 25 (Extended Data Fig. 1a,b). The purified protein was aliquoted and stored at $-80^{\circ} \mathrm{C}$ before use. The purity of IL-10/Fc was confirmed with sodium dodecyl sulphate polyacrylamide gel electrophoresis (SDS-PAGE, Extended Data Fig. 1c).

\section{Preparation of PMEL, WT OT-I, MPC1-KO OT-I, Tcf7DTR-GFP P14 T cells, and human CD8+ T cells}

Spleens from PMEL or OT-I mice were mechanically disrupted and grounded through a 70$\mu \mathrm{m}$ strainer (Fisher Scientific). Red blood cells (RBC) were lysed with ACK lysis buffer (2 $\mathrm{mL}$ per spleen, Gibco / Thermo Fisher Scientific) for $5 \mathrm{~min}$ at $25^{\circ} \mathrm{C}$. The splenocytes were washed twice with cold complete RPMI medium, which contained RPMI-1640 (Gibco), FBS (10\% v/v), HEPES (pH 7.2 7.5, $1 \% \mathrm{v} / \mathrm{v})$, penicillin/streptomycin $(1 \% \mathrm{v} / \mathrm{v})$, sodium pyruvate (1\% v/v, Gibco / Thermo Fisher Scientific), and 2-mercaptoethanol (0.1\% v/v, Gibco / Thermo Fisher Scientific). Splenocytes were then resuspended at a cell density of 2 $\times 10^{6} / \mathrm{mL}$ in complete RPMI medium supplemented with mouse IL-2 $(10 \mathrm{ng} / \mathrm{mL})$ and IL-7 ( $1 \mathrm{ng} / \mathrm{mL}$, PeproTech), as well as human gp10025-33 or OVA $257-264$ peptide $(1 \mu \mathrm{M}$, GenScript) for PMEL or OT-I T cells, respectively. After a 3-day culture, live cells were enriched by density gradient centrifugation against Ficoll-Paque PLUS (GE Healthcare), 
followed by another 2-day culture at a cell density of $0.5 \sim 1.0 \times 10^{6} / \mathrm{mL}$ in complete RPMI medium supplemented with mouse IL-2 $(10 \mathrm{ng} / \mathrm{mL})$ and IL-7 $(10 \mathrm{ng} / \mathrm{mL})$ to afford activated $\mathrm{CD}^{+} \mathrm{T}$ cells with purity $>95 \%$ (flow cytometry analyses). MPC1-KO OT-I T cells were prepared similarly as WT OT-I T cells. Peptide-primed CD ${ }^{+} \mathrm{T}$ cells were next used for $\mathrm{ACT}$ in mice. For in vitro experiments, the peptide-primed $\mathrm{CD} 8^{+} \mathrm{T}$ cells were cultured in complete RPMI medium supplemented with IL-2 $(10 \mathrm{ng} / \mathrm{mL})$ and IL-7 $(10 \mathrm{ng} / \mathrm{mL})$ for another 2 days to afford primed $\mathrm{CD} 8^{+} \mathrm{T}$ cells in resting phase (day 7). In the pyruvate feeding experiment, primed $\mathrm{CD} 8^{+} \mathrm{T}$ cells in resting phase were cultured in RPMI medium with low-glucose (1-g/L D-glucose, Thermo Fisher Scientific), FBS (10\% v/v), HEPES (pH $7.2 \sim 7.5,1 \% \mathrm{v} / \mathrm{v})$, penicillin/streptomycin $(1 \% \mathrm{v} / \mathrm{v})$, and 2-mercaptoethanol $(0.1 \% \mathrm{v} / \mathrm{v})$, which was further supplemented with IL-2 $(10 \mathrm{ng} / \mathrm{mL})$ and sodium pyruvate at different concentrations for 2 days.

$T c f 7^{\text {DTR-GFP }}$ P14 T cells were isolated from splenocytes of $T c f 7^{\text {DTR-GFP }}$ P14 mice by mashing the spleen through a $100 \mu$ m nylon cell strainer (BD Falcon). Red blood cells were lysed with ACK lysis buffer. For Fig. 3e,f and Extended Data Fig. 3h,i, CD8 ${ }^{+} \mathrm{T}$ cells isolated using mouse $\mathrm{CD} 8^{+} \mathrm{T}$ cell negative enrichment kit (StemCell Technologies) were activated on plates coated with anti-mouse CD3 antibody (17A2, eBioscience / Thermo Fisher Scientific) and anti-CD28 antibody (37.51, eBioscience / Thermo Fisher Scientific) plus in complete RPMI medium containing IL-2 $(50 \mathrm{ng} / \mathrm{ml})$ for 2 days before adoptive

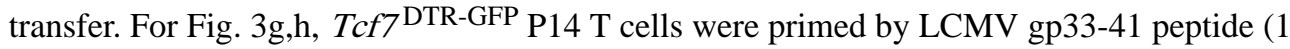
$\mu \mathrm{M}$, GenScript) and prepared similarly as described above for PMEL T cells.

Human peripheral blood mononuclear cells (PBMCs) from anonymous healthy donors (prepared as buffycoats) were activated in vitro with anti-human CD3 (OKT3, BioLegend) and CD28 (CD28.2, BioLegend) antibodies in the presence of human IL-2 $(10 \mathrm{ng} / \mathrm{mL})$ for 2 days. Activated human $\mathrm{CD}^{+} \mathrm{T}$ cells were isolated by Ficoll density gradient separation and magnetic-activated cell sorting (MACS) using a human $\mathrm{CD} 8^{+} \mathrm{T}$ cell isolation kit (Miltenyi Biotec) for in vitro assays.

\section{Preparation of control and IL-10Ra-KO P14 T cells}

Wild type (WT) P14 CD8 ${ }^{+} \mathrm{T}$ cells were isolated from splenocytes of Cas9 knock in P14 TCR transgenic mice using CD8 negative selection kit (Miltenyi Biotec) and activated using mouse T-activator CD3/CD28 Dynabeads $®$ (Gibco / Thermo Fisher Scientific) for $24 \mathrm{~h}$ followed by 4-day expansion in complete RPMI medium containing IL-2 $(10 \mathrm{ng} / \mathrm{mL})$ prior to use. To generate control and IL-10Ra-KO P14 CD8 ${ }^{+} \mathrm{T}$ cells, WT P14 CD8 ${ }^{+} \mathrm{T}$ cells were isolated and activated for $24 \mathrm{~h}$ similarly, followed by transduction with retroviruses containing scramble control guide RNA (gRNA) or IL-10Ra-targeting gRNA on plates coated with RetroNectin $\left(5 \mu \mathrm{g} / \mathrm{cm}^{2}\right.$, Clonetech / Takara). Transduced CD $8^{+} \mathrm{T}$ cells were then expanded similarly for additional 4 days prior to use. The pool of gRNAs targeting IL-10Ra (IL-10Ra 1: 5'-TCTGGCTTCAAACCACACAT-3', IL-10Ra2: 5'GCAGTGTTTACTTATCACGA-3', IL-10Ra3: 5'-GTGGGGACAACACGGACAGT-3') and a scramble control gRNA control (5'-GCGAGGTATTCGGCTCCGCG-3') were designed using the publicly available online gRNA design tool CRISPick ${ }^{54}$. 


\section{Analyses of tumor infiltrating immune cells}

Thy $1.2^{+}$C57BL/6 mice were inoculated s.c. with B16F10 tumor cells $\left(1 \times 10^{6}\right)$ and received intravenous (i.v.) adoptive transfer of PMEL CD8 ${ }^{+} \mathrm{T}$ cells $\left(5 \times 10^{6}\right)$ on day 6 post tumor inoculation followed by 4 doses (or as indicated) of peritumoral (p.t.) administration of IL-10/Fc $(20 \mu \mathrm{g})$ or PBS control every other day starting from day 6. For BrdU experiments, mice were administered BrdU (0.8 mg, Sigma-Aldrich) via intraperitoneal (i.p.) injection one day before tumor harvest. On day 14 (or as indicated), tumors were dissected from the surrounding tissues, weighed, mechanically minced, and stirred at $1000 \mathrm{rpm}$ in RPMI-1640 medium with collagenase Type IV (1 mg/mL, Gibco / Thermo Fisher Scientific), dispase II (100 $\mu \mathrm{g} / \mathrm{mL}$, Sigma-Aldrich), hyalurondase (100 $\mu \mathrm{g} / \mathrm{mL}$, Sigma-Aldrich), and DNase I (100 $\mu \mathrm{g} / \mathrm{mL}$, Sigma-Aldrich) at $37^{\circ} \mathrm{C}$ for $60 \mathrm{~min}$ for digestion. RBC lysis was performed on the digested tumor samples with ACK lysing buffer. Tumor infiltrating leukocytes were then enriched by density gradient centrifugation against Percoll (GE Healthcare), resuspended in PBS with bovine serum albumin ( $0.2 \%$, wt/v, Sigma-Aldrich), stained with indicated antibodies, and analyzed with flow cytometry. For mice bearing B16F10-OVA tumors and receiving adoptive transfer of either MPC1-KO or WT OT-I T cells, or mice bearing B16gp33 tumors and receiving adoptive transfer of either WT control P14, IL-10Ra-KO P14, or $T c f 7^{\text {DTR-GFP }}$ P14 T cells, immune cell infiltrates in tumor were analyzed in a similar way as described above.

\section{Co-transfer of PMEL and OT-I CD8+ $T$ cells}

Thy $1.2^{+}$C57BL/6 mice were sublethally lymphodepleted by total body irradiation (4 Gy) on day -4 , followed by i.v. adoptive co-transfer of Thy $1.1^{+}$naïve PMEL $\left(2 \times 10^{6}\right)$ and CD45.1 $1^{+}$ naïve OT-I CD8 ${ }^{+} \mathrm{T}$ cells $\left(2 \times 10^{6}\right)$ on day -3 (Fig. 3a-d). On day 0 , mice were inoculated with B16F10 tumor cells $\left(5 \times 10^{5}\right)$ s.c. and then treated with i.v. adoptive transfer of activated Thy $1.2^{+}$PMEL CD ${ }^{+}$T cells $\left(5 \times 10^{6}\right)$ on day 10 followed by p.t. administration of IL-10/Fc $(20 \mu \mathrm{g})$ or PBS control every other day starting from day 10 (4 doses in total). On day 17 , mice were sacrificed and tumor infiltrating lymphocytes (TILs) were analyzed by flow cytometry as described above.

\section{Co-transfer of WT and MPC1-KO OT-I CD8+ T cells}

CD45. $1^{+} \mathrm{CD} 45.2^{+}$mice were inoculated s.c. with B16F10-OVA tumor cells $\left(5 \times 10^{5}\right)$ and received i.v. adoptive co-transfer of activated WT CD45.1 ${ }^{+}$OT-I CD $8^{+} \mathrm{T}$ cells and MPC1KO CD $45.2^{+}$OT-I CD8 ${ }^{+} \mathrm{T}$ cells $\left(1: 1,5 \times 10^{6}\right.$ for each) on day 6 followed by p.t. administration of IL-10/Fc (20 $\mu$ g) or PBS control every other day until day 12. On day 13, mice were sacrificed and TILs were analyzed by flow cytometry as described above.

\section{Selective depletion of progenitor exhausted T cells}

CD45.1 ${ }^{+}$CD45.2 ${ }^{+}$C57BL/6 mice were inoculated s.c. with B16-gp33 tumor cells $\left(2.5 \times 10^{5}\right)$ and received lymphodepletion treatment $(5 \mathrm{~Gy})$ to deplete the endogenous lymphocytes one day prior to i.v. adoptive transfer of CD45.2 $2^{+} T c 7^{\text {DTR-GFP }}$ P14 T cells $\left(1 \times 10^{5}\right)$ on day 11 . Mice were p.t. administrated with IL-10/Fc (20 $\mu$ g) or PBS control every other day starting from day 11 (7 doses in total). To deplete the diphtheria toxin receptor (DTR) expressing cells, diphtheria toxin (DT, Sigma-Aldrich) was injected i.p. twice (day 15 and 16) at a dose 
of $50 \mu \mathrm{g} / \mathrm{kg}$. TILs were analyzed on day 25 similarly as described above. In a therapeutic study (Fig. 3g,h), C57BL/6 mice were inoculated s.c. with B16-gp33 tumor cells $\left(5 \times 10^{5}\right)$ and received i.v. adoptive transfer of $T c f 7^{\text {DTR-GFP }}$ P14 T cells $\left(2.5 \times 10^{6}\right)$ on day 6 followed by p.t. administration of IL-10/Fc (20 $\mu$ g) or PBS control through every other day starting from day 6 (4 doses in total). DT was injected i.p. on day 6,8 and 10 at a dose of $50 \mu \mathrm{g} / \mathrm{kg}$. Tumor area and body weight were monitored every other day.

\section{Flow cytometry analyses}

For surface marker staining, cells were collected in U-bottom 96-well plates (Thermal Fischer Scientific), blocked with anti-mouse CD16/32 antibody (BioLegend), and incubated with indicated antibodies at $4^{\circ} \mathrm{C}$ for $20 \mathrm{~min}$, followed by live/dead staining by 4',6diamidino-2-phenylindole (DAPI, Sigma-Aldrich) or Zombie Aqua Fixable Dye (BioLegend). Cell were then washed with PBS containing bovine serum albumin $(0.2 \%$, $\mathrm{wt} / \mathrm{v}$ ) and resuspended in the same buffer for flow cytometry analyses. For intracellular staining, cells were first stained for surface markers and aqua fixable dye as described above. Next, cells were fixed and permeabilized with a Cytofix/Cy toperm ${ }^{\mathrm{TM}}$ Fixation/ Permeabilization Solution Kit (BD Biosciences) for cytokine staining or a Foxp3/ Transcription Factor Staining Buffer Set (eBioscience) for BrdU, active caspase-3, and transcription factors staining per the manufacturer's instructions, followed by incubation with indicated antibodies for intracellular staining (temperature and time per the manufacturer's instructions). For intracellular cytokine staining, cells were first stimulated by a Cell Stimulation Cocktail (protein transport inhibitors included, Invitrogen / Thermo Fisher Scientific) at $37^{\circ} \mathrm{C}$ for $4-6 \mathrm{~h}$. Cells were then processed similarly for surface marker staining and intracellular staining as described above. Data was collected using an Attune NxT Flow Cytometer with Attune NxT Software version 3 (Invitrogen / Thermal Fischer Scientific). Analyses was performed using FlowJo 10.6.1 (Tree Star). Gate margins were determined by isotype controls and fluorescence-minus-one (FMO) controls.

\section{Antibodies and reagents for flow cytometry}

The following antibodies or staining reagents were purchased from BioLegend: CD16/32 (93, 101302), Thy 1.1 (OX-7, 202529), Thy 1.2 (30-H12, 105343), CD45.1 (A20, B218971), CD45.2 (104, 109814), CD8a (53-6.7, 100714), CD8ß (YTS256.7.7, 126606), CD4 (RM4-5, 100526), NK1.1 (PK136, 108740), F4/80 (BM8,123108), CD3ع (17A2, 100306), CD19 (6D5,115520), CD44 (IM7, 103006), CD11c (N418, 117348), I-A/I-E (MHC-II, M5/114.15.2, 107643), Siglec-F (S17007L, 155508), CD80 (16-10A1, 104734), CD86 (GL-1, 105006), Foxp3 (MF-14, 126406), CD11b (M1/70, 101228), Ki67 (16A8, 652424), BrdU (3D4, 364104), Granzyme B (GB11, 515403), IFN- $\gamma$ (XMG1.2, 505826), TNF-a (MP6-XT22, 506308), IL-2 (JES6-5H4, 503822), IL-10Ra (1B1.3a, 112705), CD69 (H1.2F3, 104512), Gr-1 (RB6-8C5, 202519), PD-1 (29F.1A12, 135216), TIM-3 (RMT3-23, 119706). TCF-1 (C63D9, 2203S) was obtained from Cell Signaling Technology (Danvers, MA, USA). Active-caspase-3 (C92-605) was obtained from BD Biosciences. Alexa Fluor 488-conjugated goat anti-rabbit secondary antibody (A-11008), MitoTracker Green FM, MitoTracker Deep Red FM and MitoSOX ${ }^{\mathrm{TM}}$ Red mitochondrial superoxide indicators were obtained from Thermo Fisher Scientific. 


\section{Immunofluorescence staining}

For tumor tissue section staining, tumors were fixed in paraformaldehyde (PFA, 4\%, SigmaAldrich) overnight followed by imbedding in paraffin blocks. Paraffin slides were sectioned with a thickness of $4 \mu \mathrm{m}$. Tissue sections were rehydrated at the EPFL Histology Core Facility and stained with anti-CD3 antibody (SP7, Abcam, 1:150), followed by staining with an Alexa Fluor 488-conjugated goat anti-rabbit secondary antibody (Invitrogen / Thermo Fisher Scientific), and DAPI. Images were collected using a LSM700 confocal microscope (Zeiss) at the EPFL Bioimaging and Optics Platform.

\section{Cell sorting}

$\mathrm{CD}^{+}$TILs from B16F10 or YUMM1.7-OVA tumors or $\mathrm{CD} 8^{+} \mathrm{T}$ cells from in vitro culture were first enriched by MACS using mouse CD8 (TIL) MicroBeads (Miltenyi Biotec), and then stained with surface markers and DAPI followed by sorting with an Aria II sorter (BD Biosciences) at the EPFL Flow Cytometry Core Facility.

\section{In vitro restimulation of $\mathrm{CD}^{+} \mathrm{T}$ cells}

Activated PMEL or OT I CD8 ${ }^{+} \mathrm{T}$ cells in resting phase (day 7 in culture) were restimulated with dimerized anti-CD3 antibody [prepared by mixing anti-CD3 antibody (17A2, Bio X Cell) with goat anti-rat IgG (Invitrogen / Thermo Fisher Scientific) at the mole ratio of 2:1] in complete RPMI medium containing IL-2 (10 ng/mL) for 2 days (Extended Data Fig. 5a). Harvested cells were phenotyped with flow cytometry based on the expression level of surface inhibitory receptors (PD-1 and TIM-3). The live CD8 ${ }^{+} \mathrm{T}$ cells were analyzed by flow cytometry, or isolated by Ficoll density gradient separation for Seahorse assay. The PD $-1^{+} \mathrm{TIM}-3^{+} \mathrm{CD} 8^{+} \mathrm{T}$ cell subset was sorted for in vitro co-culture assay or Seahorse assay.

\section{Preparation of mouse and human CAR-T cells}

Constructs for mouse and human chimeric antigen receptor (CAR) targeting human epidermal growth factor receptor 2 (HER2) were generated according to previously described ${ }^{50}$. Mouse and human HER2 CAR-T cells were prepared according to a published report $^{55}$. For mouse CAR-T cells preparation, Phoenix-Eco cells were transfected with HER2 CAR-carrying plasmid and pCL-Eco-packaging plasmid using the calcium phosphate method. Viruscontaining supernatant was collected by centrifuge every $24 \mathrm{~h}$ post transfection until $72 \mathrm{~h}$. The splenocytes from WT mice were stimulated by mouse Tactivator $\mathrm{CD} 3 / \mathrm{CD} 28$ Dynabeads ${ }^{\circledR}$ for 1 day, and then transduced with the virus-containing supernatant using spin transduction with centrifugation at $2,000 \mathrm{~g}$ for $2 \mathrm{~h}$ at $32^{\circ} \mathrm{C}$. After overnight incubation at $37^{\circ} \mathrm{C}$, the supernatant was replaced with fresh complete RPMI medium supplemented with mouse IL-2 $(10 \mathrm{ng} / \mathrm{mL})$. Cells were passaged every $24 \mathrm{~h}$ at a ratio of 1:2 for another 3 days before use. Transduction efficiency was determined by staining surface HER2-CAR using biotinylated human Her2/ErbB2 Protein (Acro Biosystems) and avidin-Alexa Fluor ${ }^{\mathrm{TM}} 488$ conjugate (Invitrogen / Thermo Fisher Scientific) $48 \mathrm{~h}$ post transduction. Untransduced T cells activated by Dynabeads ${ }^{\circledR}$ were used as control.

To prepare human CAR-T cells, the replication-defective human HER2 CAR lentivirus was produced in HEK293T cells, which were transfected with plasmids of pVSV-G, Delta 8.9, and human HER2 CAR using the calcium phosphate method. Primary human T cells were 
isolated from the PBMCs of healthy donors and activated as described above, followed by transduction with the supernatant containing human HER2 CAR lentivirus particles on day 1 post activation using spin transduction for $2 \mathrm{~h}$ at $32^{\circ} \mathrm{C}$. Cells were passaged at a $1: 2$ ratio every day with fresh complete RPMI medium supplemented with human IL-2 (10 ng/mL, BioLegend) for another 5 days before use. Transduction efficiency was evaluated as describes above.

\section{In vitro co-culture of T cells and tumor cells}

B16F10 tumor cells were cultured in complete DMEM medium as described above. Harvested B16F10 tumor cells were seeded in 24 or 96-well microplates or flasks in complete DMEM medium at $37^{\circ} \mathrm{C}$ for 2 days. Following aspiration of tumor culture medium, activated PMEL CD $8^{+} \mathrm{T}$ cells in resting phase as described above were suspended in complete RPMI medium supplemented with IL-2 $(10 \mathrm{ng} / \mathrm{mL})$ and added to the tumor cell culture at a $\mathrm{T}$ cell to tumor cell ratio of 1 to 1 . After another 2-day co-culture, $\mathrm{CD} 8^{+} \mathrm{T}$ cells were isolated by Ficoll density gradient separation and MACS with mouse CD8 MicroBeads (Miltenyi Biotec) for Seahorse assay and flow cytometry analyses. To determine the lysis of targeT cells, the viability of tumor cells from the co-culture was measured with DAPI staining and flow cytometry. Similarly, human HER2 CAR-T cells were co-cultured with SKOV3-HER2 or ME275-HER2 tumor cells in vitro at an effector to target ratio of 1 to 1 in the presence or absence of IL-10/Fc $(200 \mathrm{ng} / \mathrm{mL})$ for 2 days. Human CD8 ${ }^{+}$HER2 CAR-T cells were isolated by Ficoll density gradient separation and MACS using the human CD8 ${ }^{+}$ $\mathrm{T}$ cell isolation kit (Miltenyi Biotec) for Seahorse assay and flow cytometry analyses.

\section{Seahorse assay}

Seahorse assay was performed to measure oxygen consumption rate (OCR) and extracellular acidification rate (ECAR) of $\mathrm{T}$ cells. Pan $\mathrm{CD} 8^{+} \mathrm{T}$ cells or sorted subsets of mouse or human $\mathrm{CD}^{+} \mathrm{T}$ cells $\left(3 \times 10^{5} /\right.$ well $)$ with different treatment conditions were seeded in a Seahorse culture plate (Seahorse Bioscience, North Billerica, MA, USA) in non-CO2 incubator at 37 ${ }^{\circ} \mathrm{C}$ for $40 \mathrm{~min}$. OCR and ECAR were measured by an XF96 Seahorse Extracellular Flux Analyzer (Seahorse Bioscience) following the manufacturer's instructions. During a seahorse assay, cells were treated with oligomycin ( $1 \mu \mathrm{M}$, Sigma-Aldrich), Carbonyl cyanide-4-(trifluoromethoxy)phenylhydrazone (FCCP, $2 \mu \mathrm{M}$, Sigma-Aldrich), rotenone (0.5 $\mu \mathrm{M}$, Sigma-Aldrich), antimycin A (0.5 $\mu \mathrm{M}$, Sigma-Aldrich), glucose (10 mM, SigmaAldrich), and 2-Deoxy-D-glucose (2-DG, $50 \mathrm{mM}$, Sigma-Aldrich). Each condition was performed with 3-6 replicates in a single experiment. OXPHOS and glycolysis were calculated according to the previous report ${ }^{56}$.

\section{Metabolic inhibitor treatments}

Activated PMEL CD8 ${ }^{+} \mathrm{T}$ cells in resting phase (day 7 in culture) as described above were restimulated with dimerized anti-CD3 antibody in complete RPMI medium containing IL-2 $(10 \mathrm{ng} / \mathrm{mL})$ and indicated inhibitors [2-DG, $0.5 \mathrm{mM}$; Oligomycin, $1 \mu \mathrm{M}$; Etomoxir (ETO Sigma-Aldrich), $200 \mu \mathrm{M}$; Bis-2-(5-phenylacetamido-1,3,4-thiadiazol-2-yl)ethyl sulfide (BPTES, Sigma-Aldrich), $20 \mu \mathrm{M}$; or UK5099 (Sigma-Aldrich), $100 \mu \mathrm{M}$ ] for 2 days in the presence or absence of IL-10/Fc (200 ng/mL). Live CD ${ }^{+} \mathrm{T}$ cell counts were determined by 
flow cytometry analyses. Pan $\mathrm{CD} 8^{+} \mathrm{T}$ cells or sorted subsets of $\mathrm{CD} 8^{+} \mathrm{T}$ cells were prepared for Seahorse assay as described above.

\section{Anti-tumor therapy and rechallenging experiments}

Mice bearing established tumors with area around 25-60 $\mathrm{mm}^{2}$ (day 6 post inoculation or as indicated), were treated with adoptive transfer of activated PMEL, OT-I CD8 ${ }^{+} \mathrm{T}$ cells, MPC1-KO OT-I, and Tcf $7^{\text {DTR-GFP }}$ P14 T cells, or HER2 CAR T cells $\left(5 \times 10^{6}\right.$ or as indicated) followed by p.t. administration of IL-10/Fc ( $20 \mu \mathrm{g})$ or PBS control every other day (or as indicated) starting from day 6 (4 or 8 doses in total as indicated). Mice receiving p.t. administration of PBS control only, IL-10/Fc only, or untransduced $\mathrm{T}$ cells served as controls. Tumor area and body weight were measured every other day. Tumor area was calculated by the formula Area $=$ Length $\times$ Width from calliper measurements of 2 orthogonal diameters. Mice were euthanized when body weight loss was beyond $15 \%$ of pre-dosing weight, or tumor area reached $150 \mathrm{~mm}^{2}$ (as a predetermined endpoint), or the animal had become moribund. In tumor-cell rechallenging experiments, B16F10 $\left(1 \times 10^{5}\right)$, YUMM1.7-OVA $\left(5 \times 10^{5}\right)$, MC38-HER2 $\left(1 \times 10^{6}\right)$, or CT26 $\left(3 \times 10^{5}\right)$ cells were reimplanted s.c. into the left flanks of survived mice from treatment groups at day 90 post primary inoculation. Age-matched naïve WT mice were s.c. inoculated with the same number of tumor cells as control. Survival of rechallenged mice was monitored for at least another 60 days.

\section{Combination therapy of anti-PD-1 and IL-10/Fc}

$\mathrm{BALB} / \mathrm{c}$ mice were s.c. inoculated with CT26 mouse colon cancer cells $\left(3 \times 10^{5}\right)$. The mice bearing established tumors with area around $25-30 \mathrm{~mm}^{2}$ (day 6 post inoculation) were injected p.t. with anti-PD-1 antibody (100 $\mu$ g per injection, RMP1-14, Bio X Cell) on day 6 , 9 , and 12 along with p.t. administration of IL-10/Fc ( $20 \mu \mathrm{g}$ per injection) every other day from day 6 to 14. Mice receiving administration of PBS only, IL-10/Fc only, or anti-PD-1 antibody only served as controls. Tumor area and body weight were measured every other day.

\section{Measurement of liver enzymes}

Thy $1.2^{+}$C57BL/6 mice were inoculated s.c. with B16F10 tumor cells $\left(1 \times 10^{6}\right)$ and received i.v. adoptive transfer of activated Thy $1.1^{+}$PMEL $\mathrm{CD}^{+} \mathrm{T}$ cells $\left(5 \times 10^{6}\right)$ on day 6 followed by p.t. administration of IL-10/Fc (20 $\mu$ g) or PBS control every other day until day 12 . On day 14, mice were sacrificed and serum samples were collected for analyses. The levels of alanine transaminase (ALT) and aspartate transaminase (AST) in serum were measured using Stanbio Chemistry Reagents (Stanbio) per the manufacturer's instructions.

\section{RNA sequencing and bioinformatics analysis}

Mice were sublethally lymphodepleted by total body irradiation (4 Gy) on day -4 , followed by i.v. adoptive transfer of Thy $1.1^{+}$naïve PMEL T cells $\left(2 \times 10^{6}\right)$ on day -3 , and inoculation with B16F10 tumor cells on day 0. On day 10, mice were treated with i.v. adoptive transfer of Thy $1.2^{+}$activated PMEL CD8 ${ }^{+}$T cells $\left(5 \times 10^{6}\right)$ prepared as described above, followed by p.t. administration of IL-10/Fc ( $20 \mu \mathrm{g})$ or PBS control every other day starting from day 
10 (4 doses in total). On day 18 , mice were sacrificed and TILs were isolated as described above. Thy $1.1^{+} \mathrm{PD}-1^{+} \mathrm{TIM}-3^{+} \mathrm{CD} 8^{+}$TILs (500 cells, purity > 99\%) were sorted into HardShell® 96-Well PCR Plates (Bio-Rad) containing Triton X-100 (0.2\%) with RNase inhibitor (Takara) and stored at $-80^{\circ} \mathrm{C}$ until library preparation. Libraries were sequenced based on published protocol ${ }^{57}$. RNA sequencing data was collected on a HiSeq3000 (Illumina) with the software of Real-time Analysis (RTA). The RNA sequencing raw data were processed through the standard RNA-seq analysis pipeline at NYUAD. Briefly, raw read alignment was performed using tophat2 v2.1.0, with the parameters "-no-novel-junctions" and "-G" when specifying the genome file. The reference genome and GFF annotation correspond to the Mus musculus GRCm38.p4 genome version. Following the tophat2 alignment, read counts mapped to each gene were generated using HTseq count. The differential expression analysis of the raw counts was performed based on the DESeq2 R library. The false discovery rate (FDR)-adjusted $P$ values after Benjamini-Hochberg correction for multipletesting were used as the statistics to define the differential expression. The adjusted $P$ value cut-offs for the final lists of differentially expressed genes (DEGs) were as follows: IL-10/Fc vs. PBS: 842 DEGs with adjusted $P$ value smaller than 0.05 . Heat maps were created using $\log 2$ fold change of genes identified as differentially expressed by DESeq2 (adjusted $P$ value $<0.05)$. Rows were centred and scaled using z-scores. Gene set enrichment analysis were done using GSEA_4.0.2 and gene sets in the MSigDB database (C2 and C7) on z-scores against a gene set permutation. Canonical pathway analysis was performed by using QIAGEN Ingenuity Pathway Analysis (IPA).

\section{Immunoblot analysis}

Briefly, in vitro cultured PMEL CD8 ${ }^{+} \mathrm{T}$ cells (day 7) were starved in FBS-free RPMI medium overnight and restimulated as described above for the indicated time. Cells were lysed in RIPA lysis buffer (Cell Signaling Technology) with $1 \times$ protease inhibitor cocktails (Cell Signaling Technology). Before electrophoresis, total cell lysates were diluted with $4 \times$ protein sample loading buffer (Invitrogen / Thermo Fisher Scientific) containing $1 \times$ reducing reagents (Invitrogen / Thermo Fisher Scientific) and incubated at $72^{\circ} \mathrm{C}$ for $10 \mathrm{~min}$. Electrophoresis of proteins from total cell lysates was performed with NuPAGE electrophoresis system (Invitrogen / Thermo Fisher Scientific). Proteins were then transferred to PVDF membrane (Invitrogen / Thermo Fisher Scientific) by Trans-Blot ${ }^{\circledR}$ SD semi-dry transfer cell (Bio-Rad) at $18 \mathrm{~V}$ for $30 \mathrm{~min}$. The PVDF membranes were blocked with $5 \% \mathrm{w} / \mathrm{v}$ nonfat dry milk (Sigma-Aldrich) and then incubated with indicated primary antibodies at $4^{\circ} \mathrm{C}$ overnight. The bands were visualized using SignalFire ${ }^{\mathrm{TM}}$ ECL reagent (Cell Signaling Technology) after incubation with horseradish peroxidase (HRP) conjugated antibodies. The primary antibodies of p-STAT3 (Tyr705, D3A7, 9145S, 1:2000), MPC1 (D2L9I, 14462S, 1:1000), and the secondary antibodies of HRP-linked anti-rabbit IgG (7074S, 1:3000) were obtained from Cell Signaling Technology. The HRP conjugated beta actin monoclonal antibody (BA3R, MA5-15739-HRP, 1:2000) was obtained from Invitrogen / Thermo Fisher Scientific.

\section{Statistical analysis}

Statistical analysis was performed using GraphPad Prism 8 (GraphPad software, Inc). Data are presented as mean \pm s.e.m. unless otherwise indicated. Comparisons of two groups were 
performed by using two-tailed unpaired Student's t test. Comparisons of multiple groups at a single time point were performed by using one-way analysis of variance (ANOVA) and Tukey's test. Survival data were analyzed using the Log-rank test. No statistically significant (NS) differences were considered when $P$-values were larger than 0.05 .

\section{Extended Data}

a
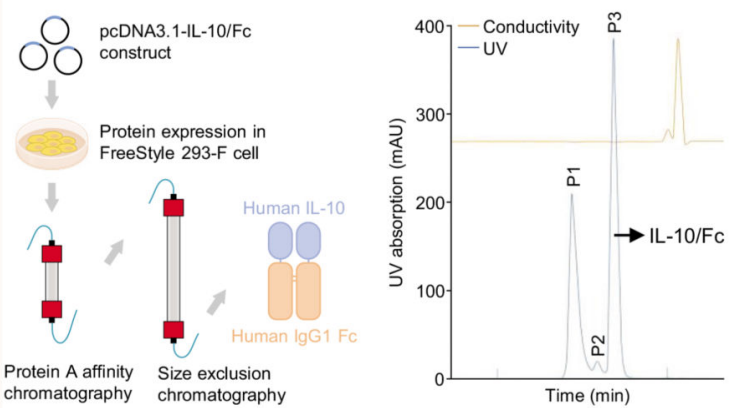

c SDS-PAGE $\mathrm{IL-10/ \textrm {Fc }}$

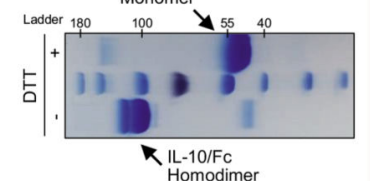

d

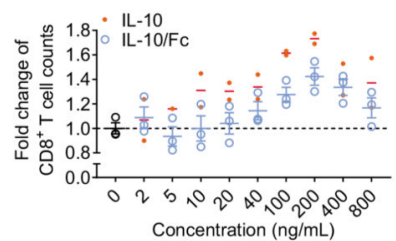

e
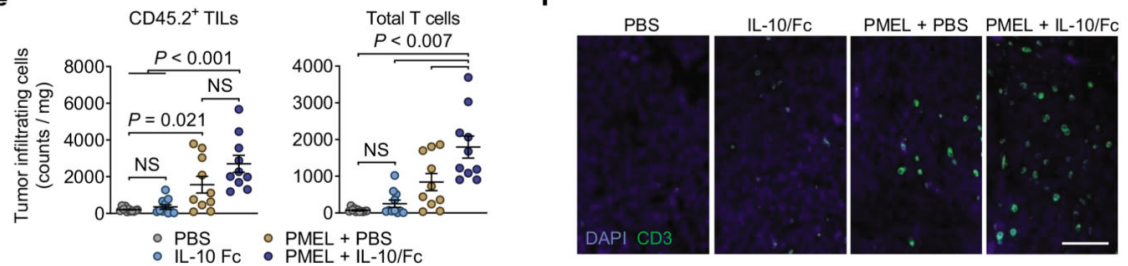

g $\odot \mathrm{PBS} \odot \mathrm{LL}-10 \mathrm{FC} \odot \mathrm{PMEL}+\mathrm{PBS} \quad \mathrm{PMEL}+\mathrm{IL}-10 / \mathrm{FC}$
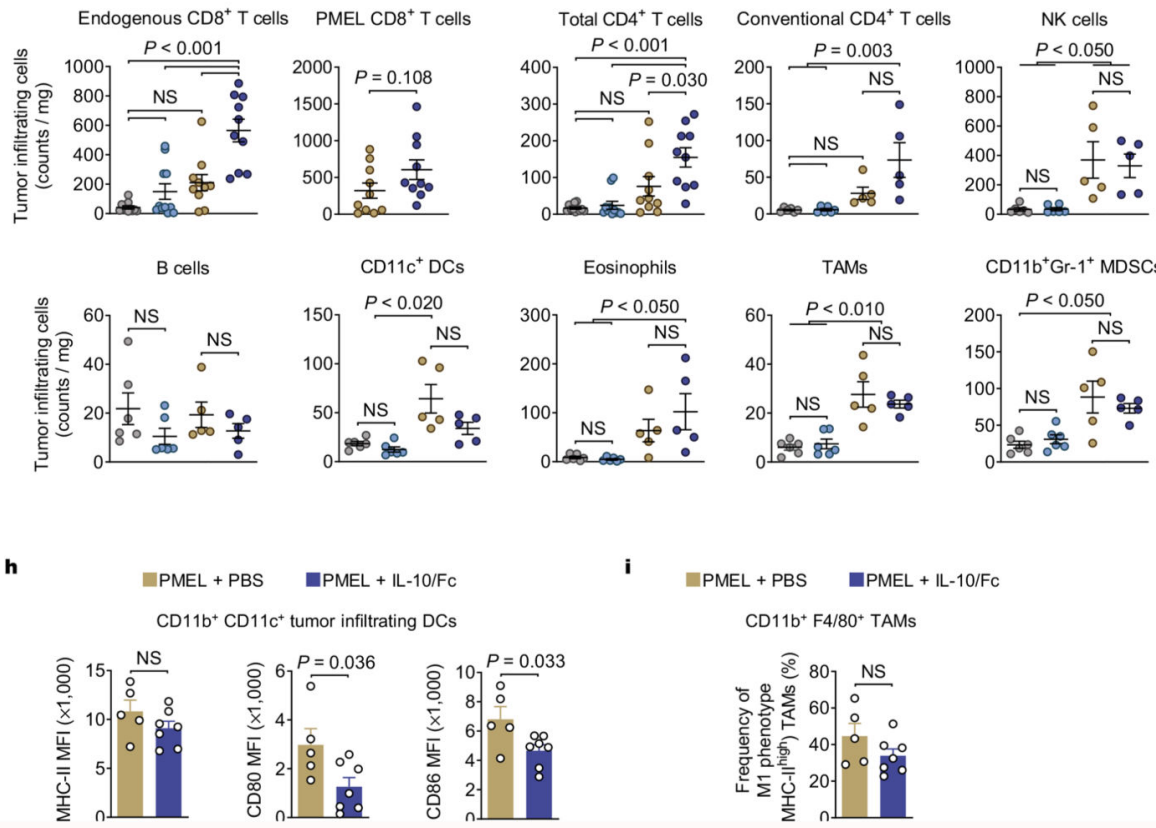

i

$\square \mathrm{PMEL}+\mathrm{PBS} \quad$ DPMEL + IL-10/FC

$\mathrm{CD} 11 \mathrm{~b}^{+} \mathrm{F} 4 / 80^{+}$TAMs

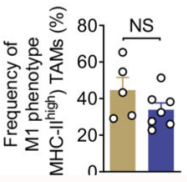

Extended Data Fig. 1. 
a
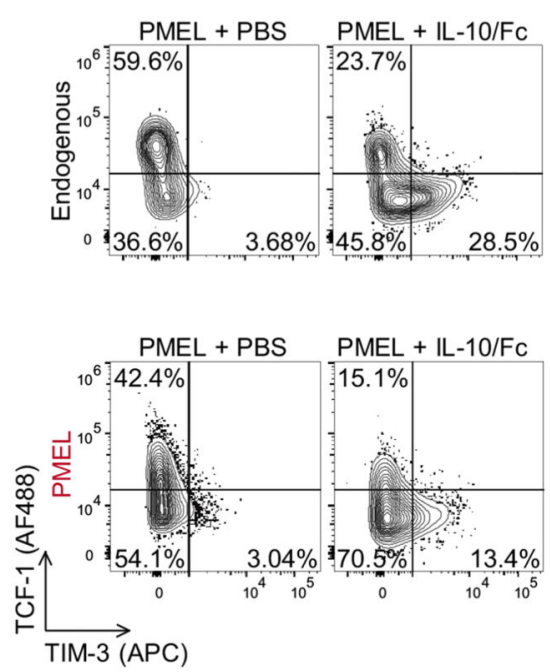

d

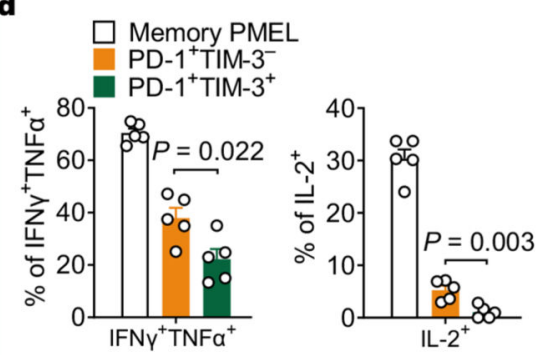

e

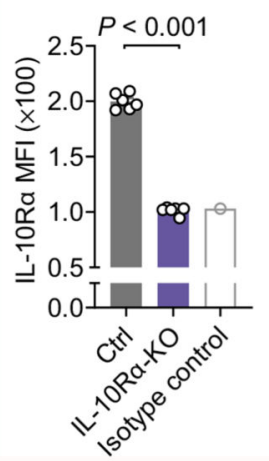

b
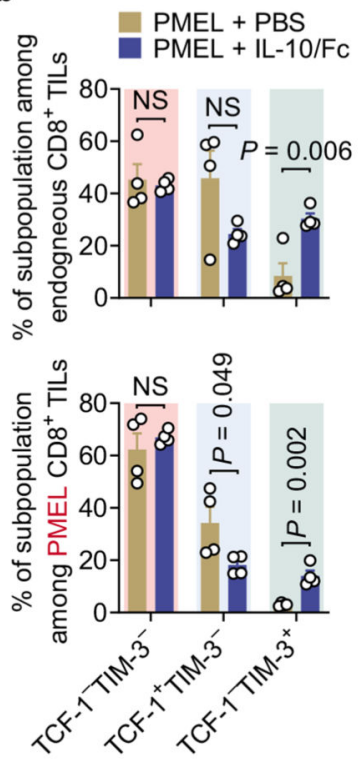

c
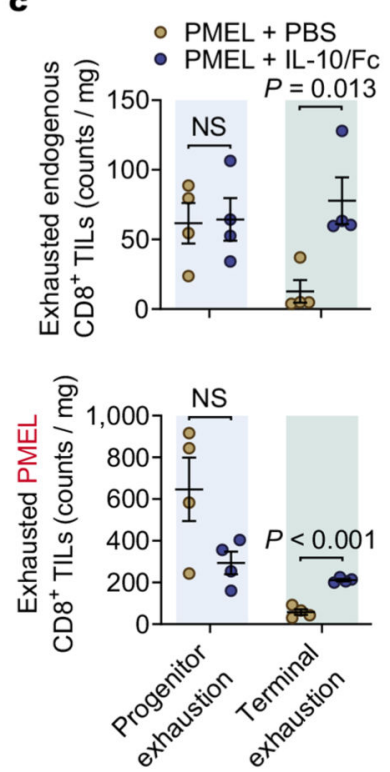

Extended Data Fig. 2. 
a

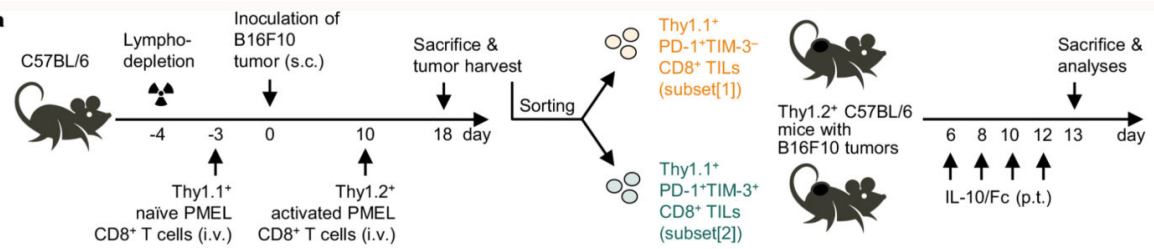

b

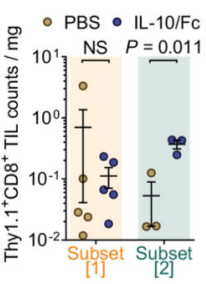

c

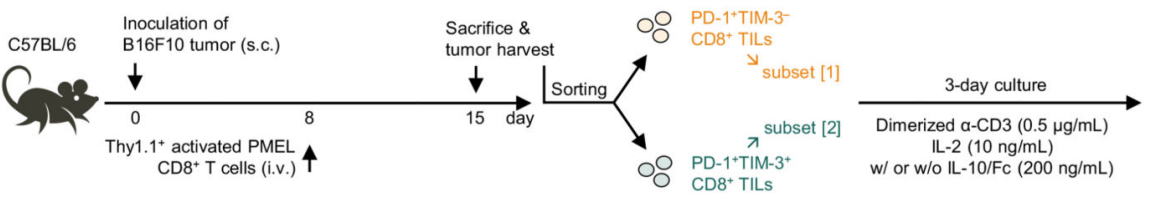

d
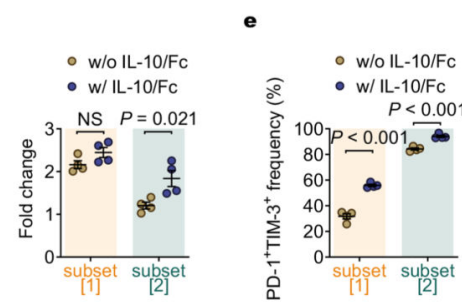

f

$\mathbf{g}$

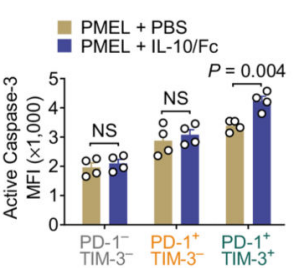

h

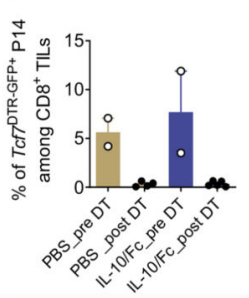

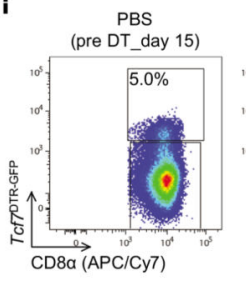

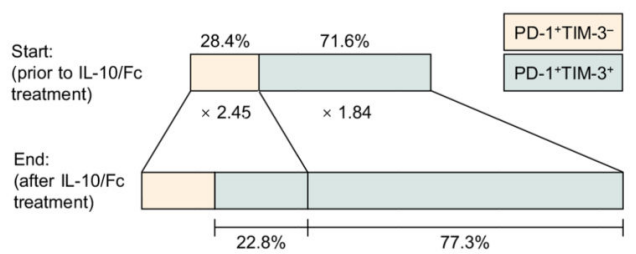

Extended Data Fig. 3.

Nat Immunol. Author manuscript; available in PMC 2021 November 24. 
a

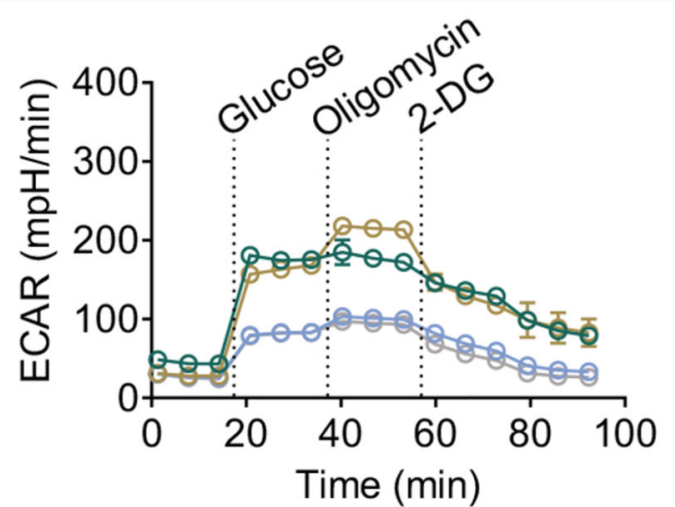

$\ominus+$ PBS $\theta+$ B16F10 + PBS

$\bullet+\mathrm{IL}-10 / \mathrm{Fc} \theta+\mathrm{B} 16 \mathrm{~F} 10+\mathrm{IL}-10 / \mathrm{Fc}$ b

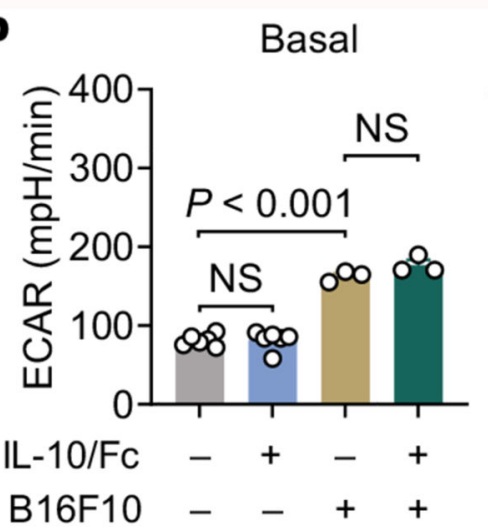

Maximal

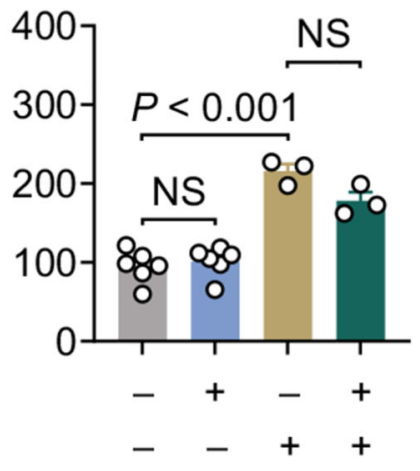

Extended Data Fig. 4.

a

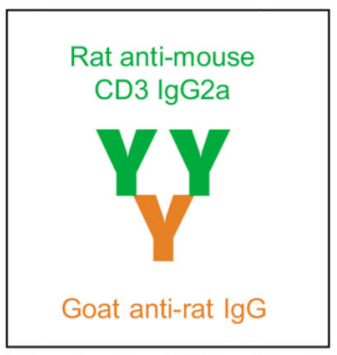

Dimerized $\alpha-C D 3$ antibody
Dimerized $\alpha-C D 3$ antibody $(\mu \mathrm{g} / \mathrm{mL})$ :

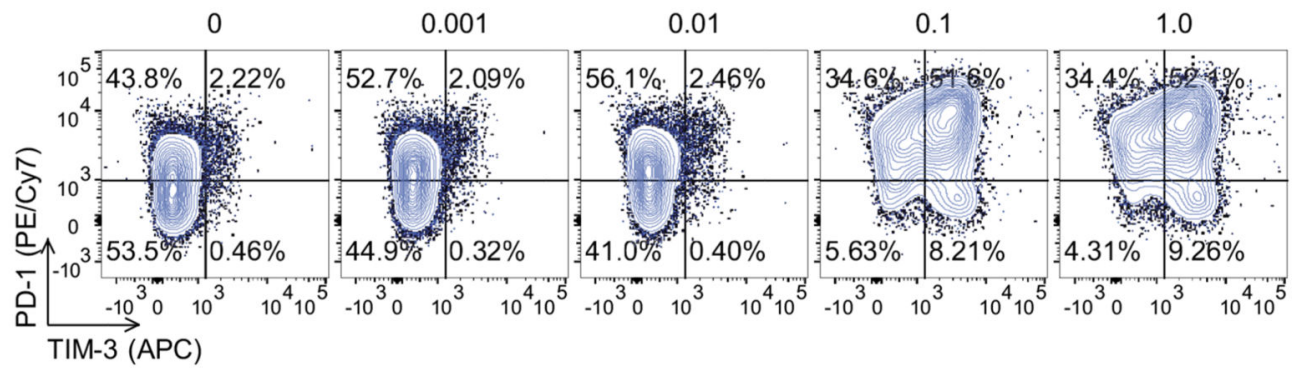

b
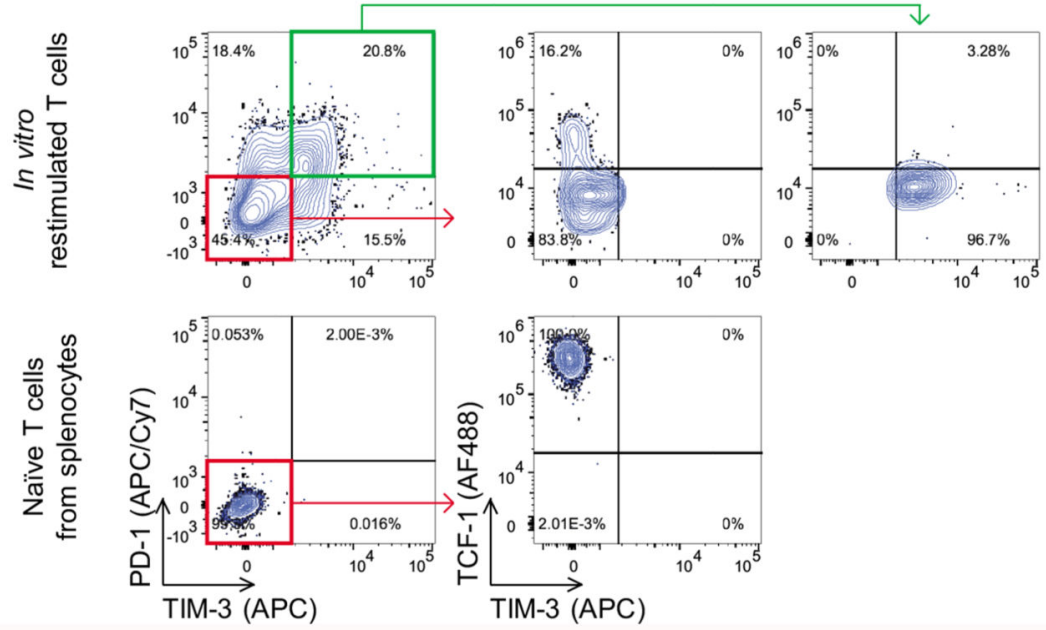

Extended Data Fig. 5. 
a

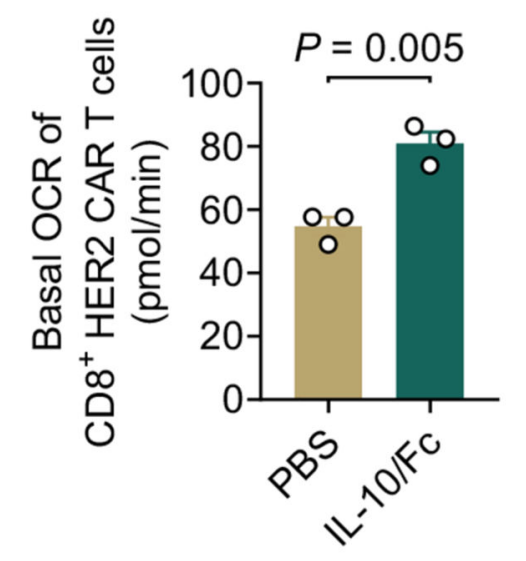

d

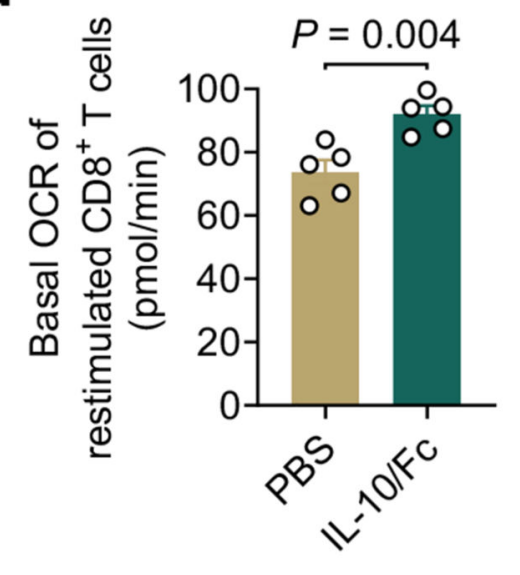

b

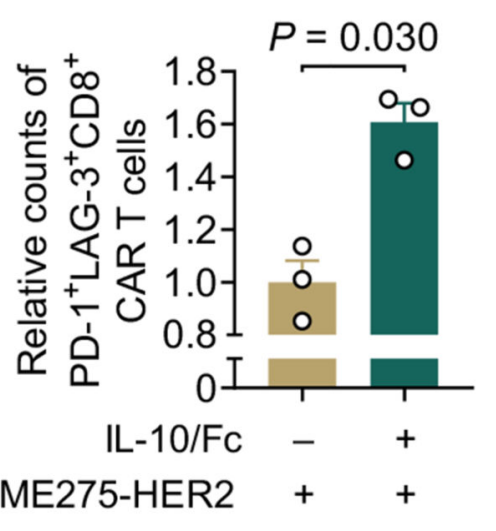

e

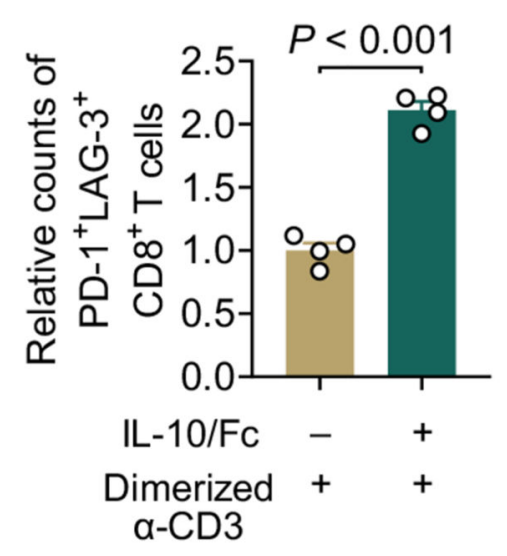

c

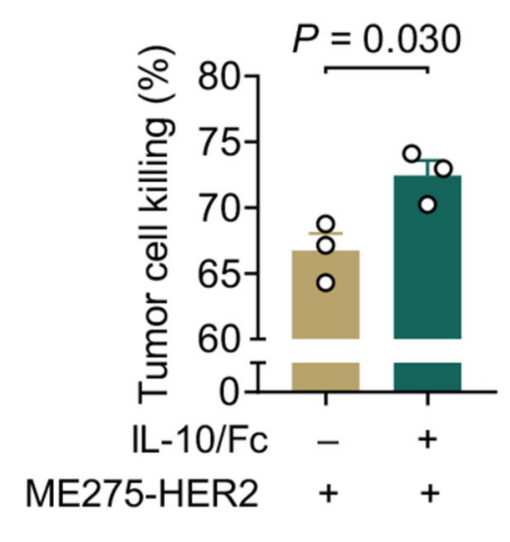

f

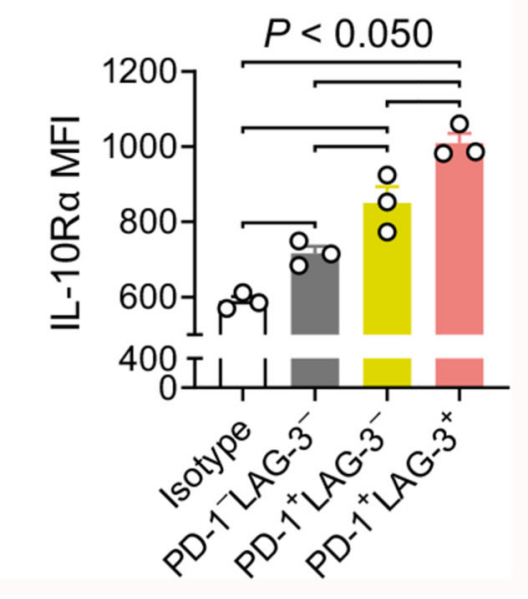

Extended Data Fig. 6. 
a B16F10:
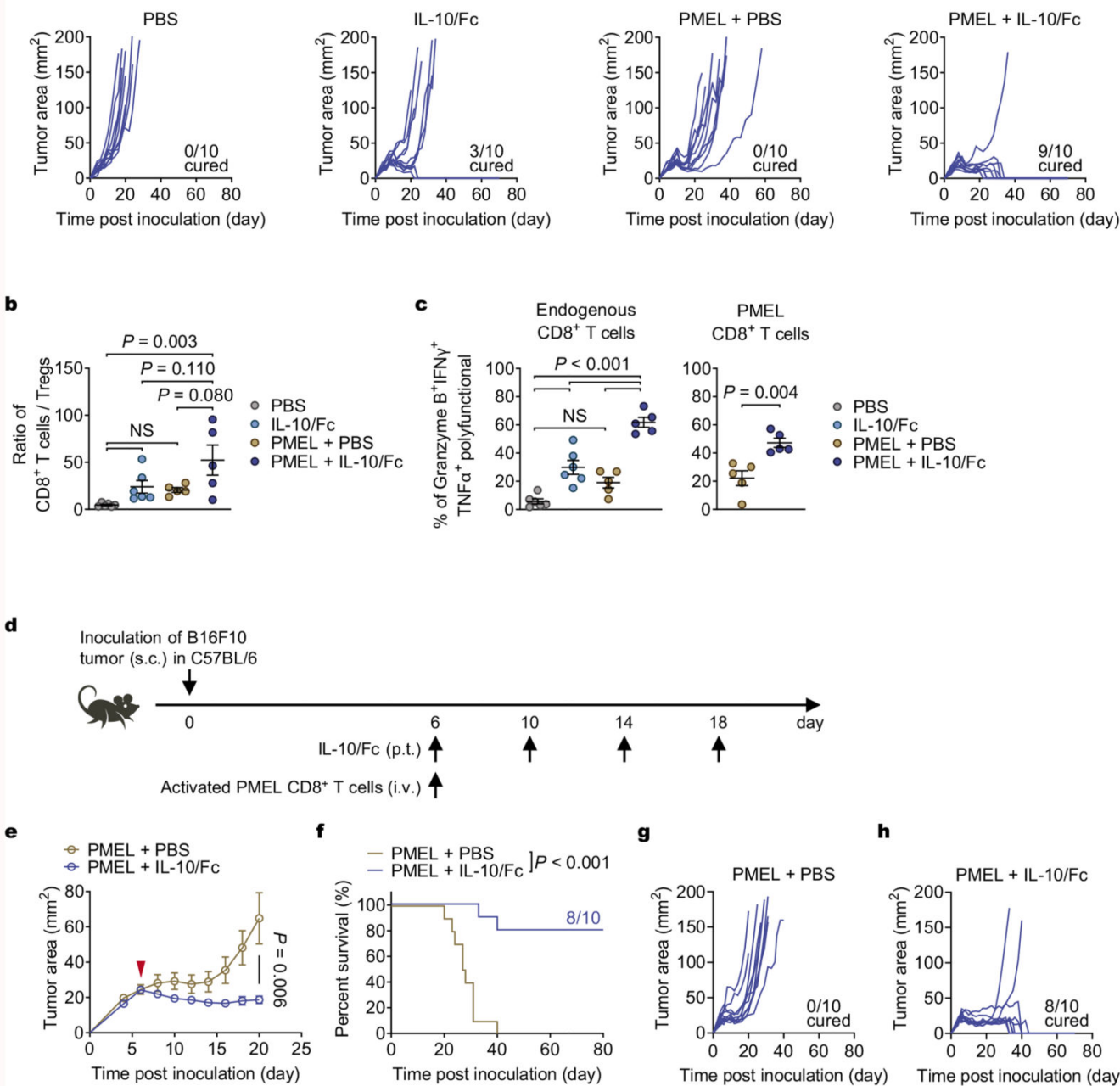

g

h
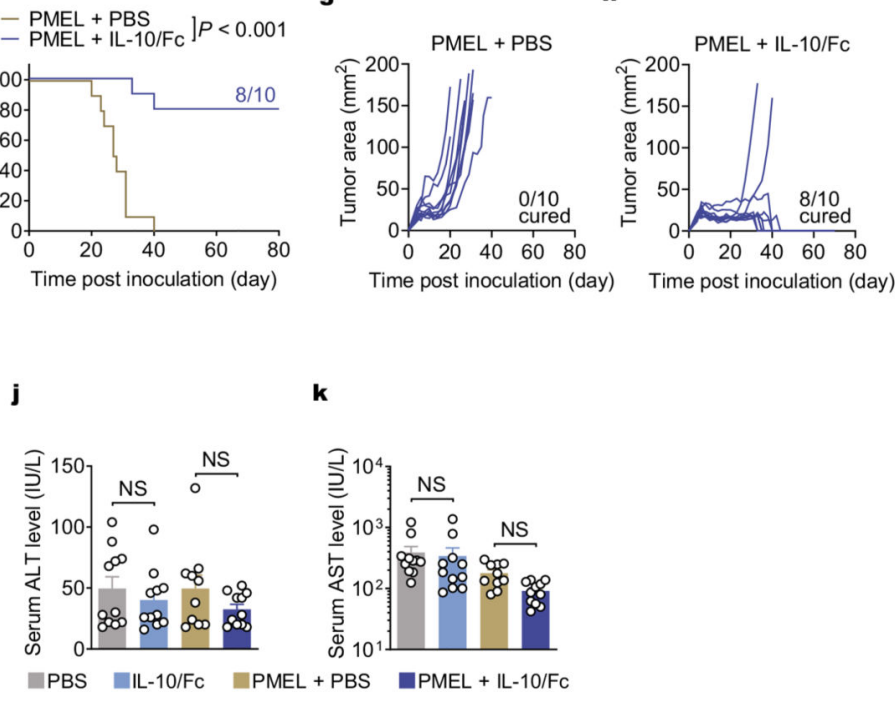

\section{Extended Data Fig. 7.}


a

Inoculation of CT26 colon carcinoma cells (s.c.) on $\mathrm{BALB} / \mathrm{c}$ mice

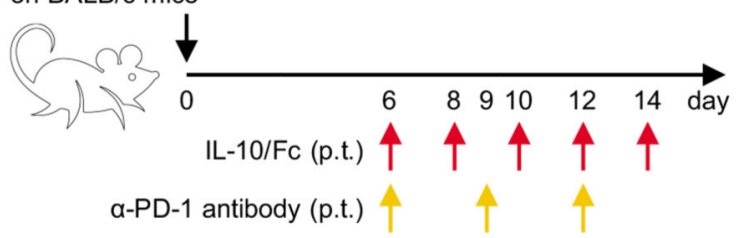

c

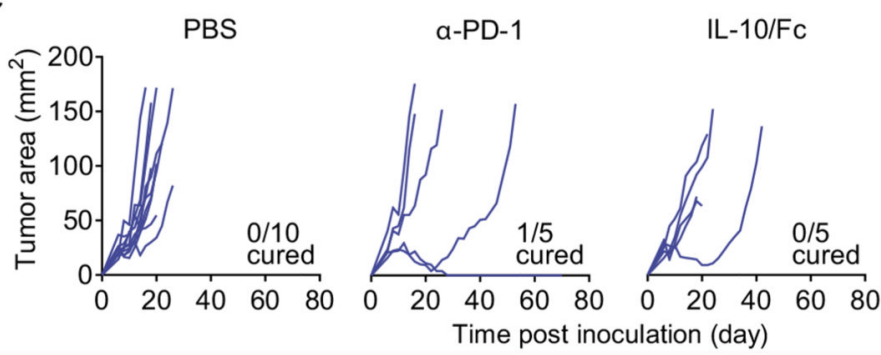

b

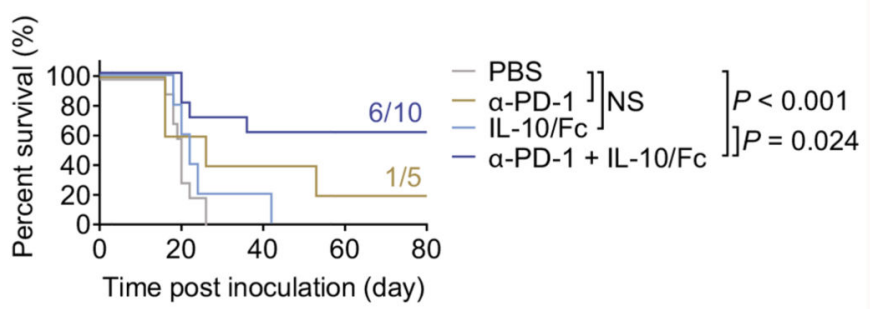

Extended Data Fig. 8.

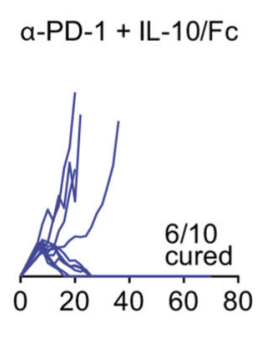

d

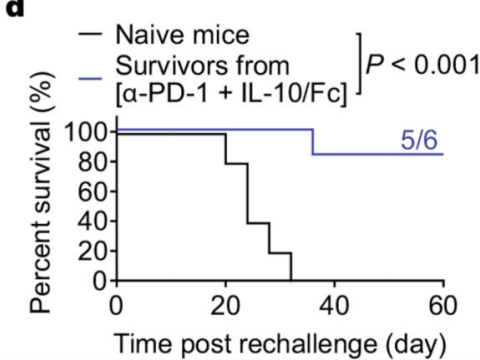


a

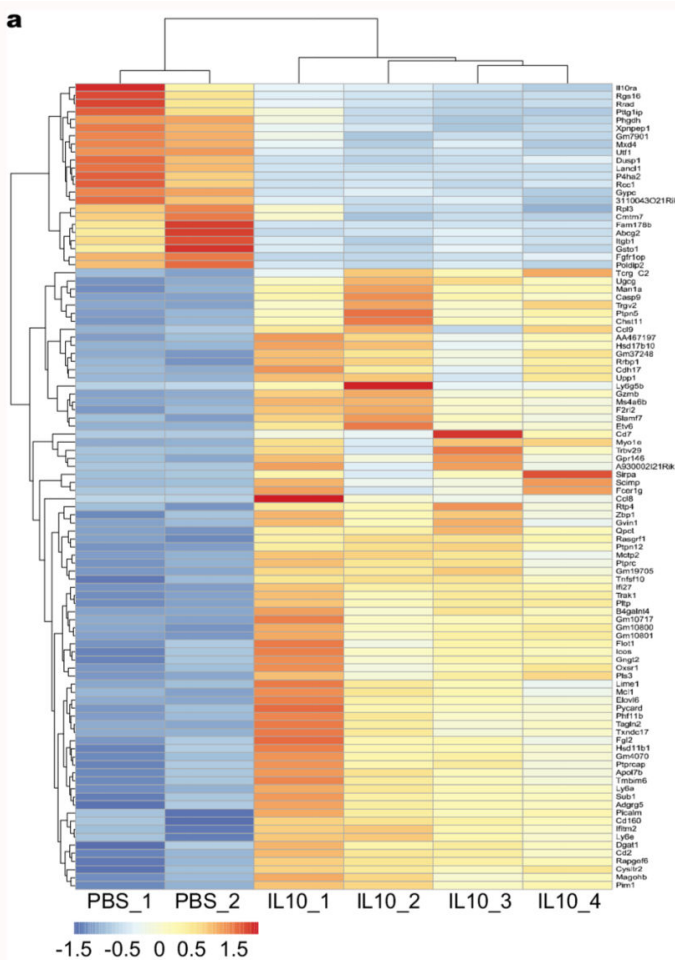

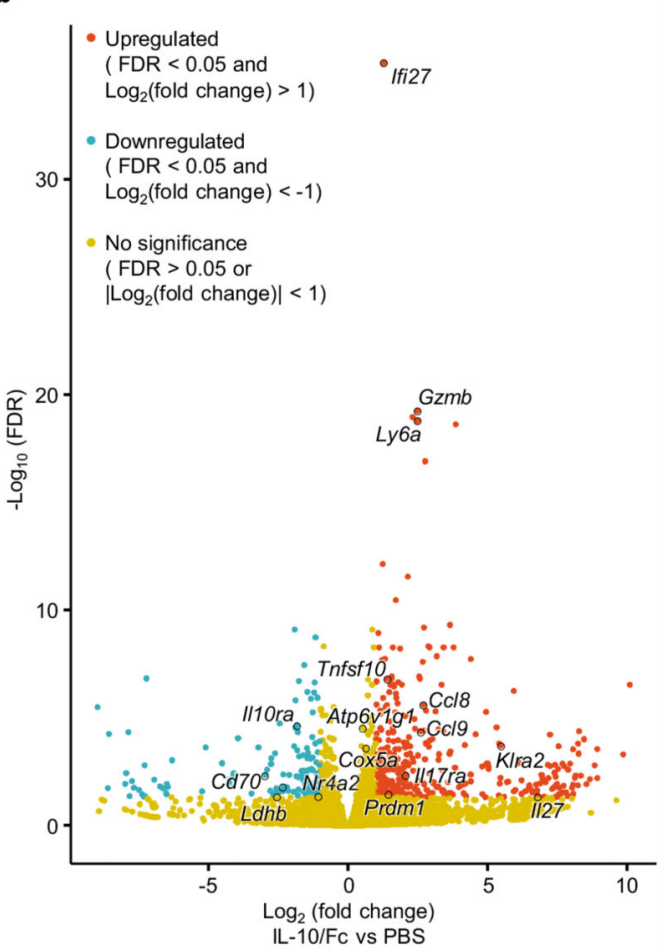

c

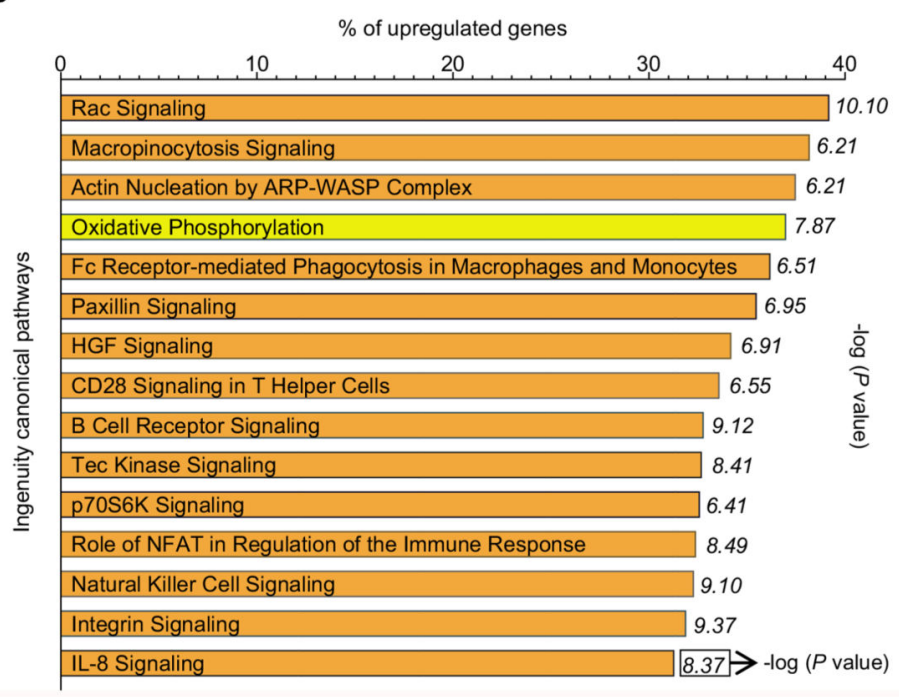

d

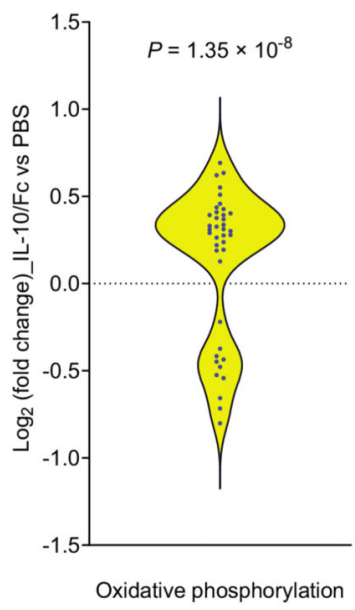

\section{Extended Data Fig. 9.}


$\mathbf{a}$

Mitochondrial mass

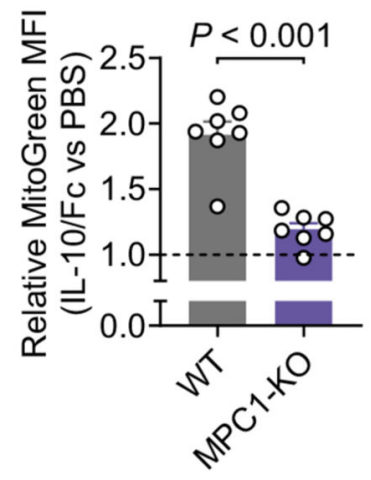

d

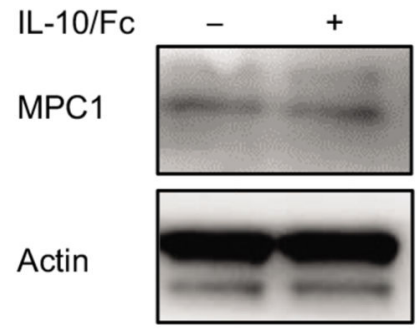

b

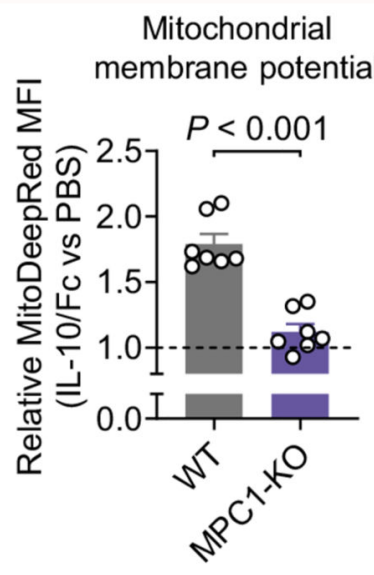

C

Mitochondrial ROS

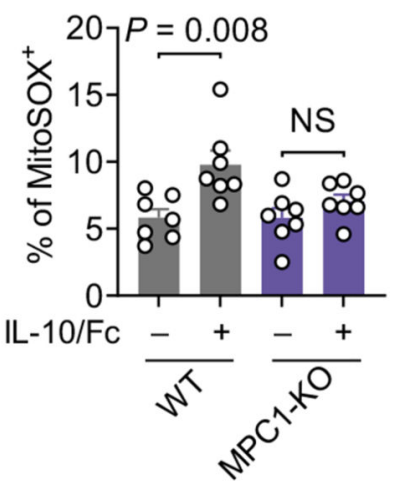

e

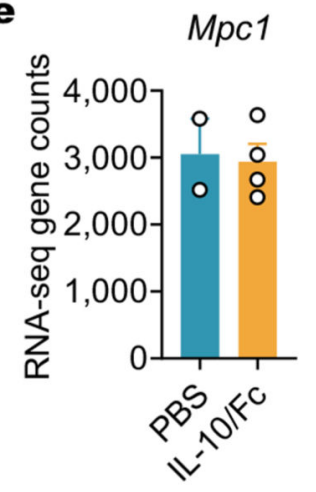

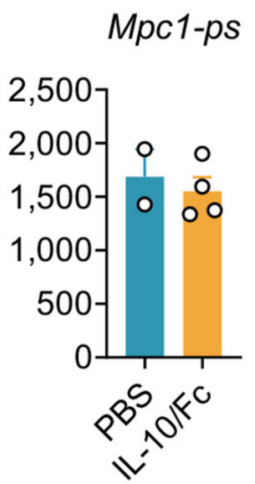

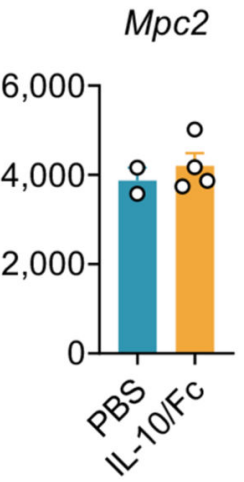

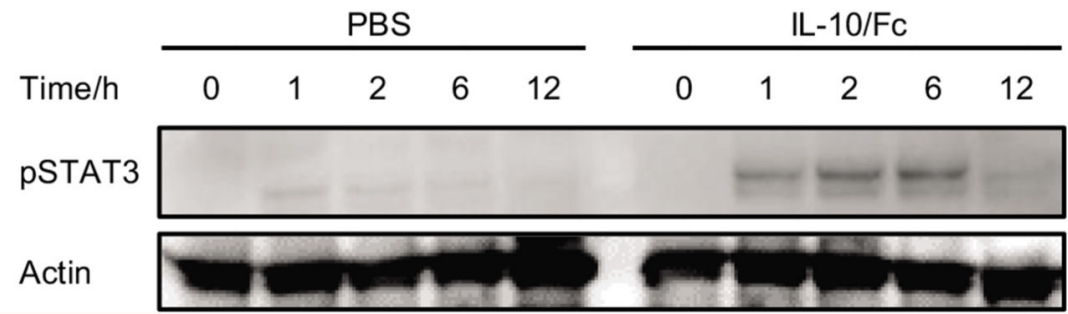

Extended Data Fig. 10.

\section{Acknowledgements}

We thank D. Trono and B.E. Correia for providing plasmids of Delta 8.9 and pVSV-G; J.-C. Martinou (University of Geneva) for providing $M p c f^{f f}$ mice; and A. Donda (University of Lausanne) for the technical support on human CAR T cells. We acknowledge the EPFL Center of PhenoGenomics, Flow Cytometry Core Facility, and Protein Expression Core Facility for technical assistance. This work was supported in part by the Swiss National Science Foundation (SNSF Project grant 315230_173243), ISREC Foundation with a donation from the Biltema Foundation, Swiss Cancer League (No. KFS-4600-08-2018), the European Research Council under the ERC grant agreement MechanoIMM (805337), Kristian Gerhard Jebsen Foundation, Fondation Pierre Mercier pour la science, 
Anna Fuller Fund grant, and EPFL (L.T.). P.-C.H. was supported in part by the Swiss Institute for Experiment Cancer Research (ISREC 26075483), the SNSF project grants (31003A_163204 and 31003A_182470), the Cancer Research Institute Lloyd J. Old STAR award, and European Research Council Staring Grant (802773-MitoGuide). P. R. was supported in part by grants from the SNSF (310030_182735 and 310030E-164187). W.H. was supported in part by the Swiss Cancer League (KFS-4407-02-2018) and the SNSF (310030B_179570). W.X. was supported in part by Strategic Priority Research Program of the Chinese Academy of Sciences (XDB29030000) and the Ministry of Science and Technology of China (2016YFC1303503). M.G. was supported by the Chinese Scholarship Council (CSC, No. 201808320453).

\section{Data availability}

Gene sets in the MSigDB database (C2 and C7) were used for gene set enrichment analysis. All data generated and supporting the findings of this study are available within the paper. Source Data are provided with the online version of the paper. The RNA-Seq data for tumorinfiltrating lymphocytes are available in the Gene Expression Omnibus database under accession code GSE168990. Additional information and materials will be made available upon reasonable request.

\section{References}

1. Chen DS, Mellman I. Elements of cancer immunity and the cancer-immune set point. Nature. 2017; 541:321-330. [PubMed: 28102259]

2. Robert C, et al. Pembrolizumab versus ipilimumab in advanced melanoma. N Engl J Med. 2015; 372:2521-2532. [PubMed: 25891173]

3. Page DB, Postow MA, Callahan MK, Allison JP, Wolchok JD. Immune Modulation in Cancer with Antibodies. Annu Rev Med. 2014; 65:185-202. [PubMed: 24188664]

4. Sharma P, Hu-Lieskovan S, Wargo JA, Ribas A. Primary, Adaptive, and Acquired Resistance to Cancer Immunotherapy. Cell. 2017; 168:707-723. [PubMed: 28187290]

5. McLane LM, Abdel-Hakeem MS, Wherry EJ. CD8 T Cell Exhaustion During Chronic Viral Infection and Cancer. Annu Rev Immunol. 2019; 37:457-495. [PubMed: 30676822]

6. Thommen DS, Schumacher TN. T Cell Dysfunction in Cancer. Cancer Cell. 2018; 33:547-562. [PubMed: 29634943]

7. Chen J, et al. NR4A transcription factors limit CAR T cell function in solid tumours. Nature. 2019; 567:530-534. [PubMed: 30814732]

8. Miller BC, et al. Subsets of exhausted $\mathrm{CD} 8^{+} \mathrm{T}$ cells differentially mediate tumor control and respond to checkpoint blockade. Nat Immunol. 2019; 20:326-336. [PubMed: 30778252]

9. Siddiqui I, et al. Intratumoral Tcf $1^{+} \mathrm{PD}-1^{+} \mathrm{CD} 8^{+} \mathrm{T}$ Cells with Stem-like Properties Promote Tumor Control in Response to Vaccination and Checkpoint Blockade Immunotherapy. Immunity. 2019; 50:195-211. e10 [PubMed: 30635237]

10. Kurtulus $\mathrm{S}$, et al. Checkpoint Blockade Immunotherapy Induces Dynamic Changes in PD-1 ${ }^{-} \mathrm{CD} 8^{+}$ Tumor-Infiltrating T Cells. Immunity. 2019; 50:181-194. e6 [PubMed: 30635236]

11. LaFleur MW, et al. PTPN2 regulates the generation of exhausted CD8 ${ }^{+} \mathrm{T}$ cell subpopulations and restrains tumor immunity. Nat Immunol. 2019; 20:1335-1347. [PubMed: 31527834]

12. Paley MA, et al. Progenitor and terminal subsets of $\mathrm{CD}^{+} \mathrm{T}$ cells cooperate to contain chronic viral infection. Science. 2012; 338:1220-1225. [PubMed: 23197535]

13. He R, et al. Follicular CXCR5-expressing CD ${ }^{+} \mathrm{T}$ cells curtail chronic viral infection. Nature. 2016; 537:412-416. [PubMed: 27501245]

14. Im SJ, et al. Defining $\mathrm{CD}^{+} \mathrm{T}$ cells that provide the proliferative burst after PD-1 therapy. Nature. 2016; 537:417-421. [PubMed: 27501248]

15. Franco F, Jaccard A, Romero P, Yu YR, Ho PC. Metabolic and epigenetic regulation of T-cell exhaustion. Nat Metab. 2020; 2:1001-1012. [PubMed: 32958939]

16. Zhang L, Romero P. Metabolic Control of $\mathrm{CD} 8^{+} \mathrm{T}$ Cell Fate Decisions and Antitumor Immunity. Trends Mol Med. 2018; 24:30-48. [PubMed: 29246759] 
17. Bengsch B, et al. Bioenergetic Insufficiencies Due to Metabolic Alterations Regulated by the Inhibitory Receptor PD-1 Are an Early Driver of $\mathrm{CD}^{+} \mathrm{T}$ Cell Exhaustion. Immunity. 2016; 45:358-373. [PubMed: 27496729]

18. Scharping NE, et al. Mitochondrial stress induced by continuous stimulation under hypoxia rapidly drives T cell exhaustion. Nat Immunol. 2021; 22:205-215. [PubMed: 33398183]

19. Yu YR, et al. Disturbed mitochondrial dynamics in CD ${ }^{+}$TILs reinforce $\mathrm{T}$ cell exhaustion. Nat Immunol. 2020; 21:1540-1551. [PubMed: 33020660]

20. Vardhana SA, et al. Impaired mitochondrial oxidative phosphorylation limits the self-renewal of $\mathrm{T}$ cells exposed to persistent antigen. Nat Immunol. 2020; 21:1022-1033. [PubMed: 32661364]

21. Fujii SI, Shimizu K, Shimizu T, Lotze MT. Interleukin-10 promotes the maintenance of antitumor $\mathrm{CD}^{+}$T-cell effector function in situ. Blood. 2001; 98:2143-2151. [PubMed: 11568001]

22. Mumm JB, et al. IL-10 Elicits IFN $\gamma$-dependent tumor immune surveillance. Cancer Cell. 2011; 20:781-796. [PubMed: 22172723]

23. Tanikawa $\mathrm{T}$, et al. Interleukin-10 ablation promotes tumor development, growth, and metastasis. Cancer Res. 2012; 72:420-429. [PubMed: 22123924]

24. Naing A, et al. PEGylated IL-10 (Pegilodecakin) Induces Systemic Immune Activation, CD8 ${ }^{+} \mathrm{T}$ Cell Invigoration and Polyclonal T Cell Expansion in Cancer Patients. Cancer Cell. 2018; 34:775791. e3 [PubMed: 30423297]

25. Ip WKE, Hoshi N, Shouval DS, Snapper S, Medzhitov R. Anti-inflammatory effect of IL-10 mediated by metabolic reprogramming of macrophages. Science. 2017; 356:513-519. [PubMed: 28473584]

26. Tan JC, Indelicato SR, Narula SK, Zavodny PJ, Chou CC. Characterization of interleukin-10 receptors on human and mouse cells. J Biol Chem. 1993; 268:21053-21059. [PubMed: 8407942]

27. Wang J, Saffold S, Krauss J, Chen W, Cao X. Eliciting T cell immunity against poorly immunogenic tumors by immunization with dendritic cell-tumor fusion vaccines. J Immunol. 1998; 161:5516-5524. [PubMed: 9820528]

28. Lechner MG, et al. Immunogenicity of murine solid tumor models as a defining feature of in vivo behavior and response to immunotherapy. J Immunother. 2013; 36:477-489. [PubMed: 24145359]

29. Alfei $\mathrm{F}$, et al. TOX reinforces the phenotype and longevity of exhausted $\mathrm{T}$ cells in chronic viral infection. Nature. 2019; 571:265-269. [PubMed: 31207605]

30. Moynihan KD, et al. Eradication of large established tumors in mice by combination immunotherapy that engages innate and adaptive immune responses. Nat Med. 2016; 22:14021410. [PubMed: 27775706]

31. Pai CCS, et al. Clonal Deletion of Tumor-Specific T Cells by Interferon- $\gamma$ Confers Therapeutic Resistance to Combination Immune Checkpoint Blockade. Immunity. 2019; 50:477-492. e8 [PubMed: 30737146]

32. June CH, O'Connor RS, Kawalekar OU, Ghassemi S, Milone MC. CAR T cell immunotherapy for human cancer. Science. 2018; 359:1361-1365. [PubMed: 29567707]

33. Santos JM, et al. Adenovirus Coding for Interleukin-2 and Tumor Necrosis Factor Alpha Replaces Lymphodepleting Chemotherapy in Adoptive T Cell Therapy. Mol Ther. 2018; 26:2243-2254. [PubMed: 30017877]

34. Klapper JA, et al. High-dose interleukin-2 for the treatment of metastatic renal cell carcinoma: A retrospective analysis of response and survival in patients treated in the Surgery Branch at the National Cancer Institute between 1986 and 2006. Cancer. 2008; 113:293-301. [PubMed: 18457330]

35. Floros T, Tarhini AA. Anticancer Cytokines: Biology and Clinical Effects of Interferon-a2, Interleukin (IL)-2, IL-15, IL-21, and IL-12. Semin Oncol. 2015; 42:539-548. [PubMed: 26320059]

36. Buck MDD, et al. Mitochondrial Dynamics Controls T Cell Fate through Metabolic Programming. Cell. 2016; 166:63-76. [PubMed: 27293185]

37. Herzig $S$, et al. Identification and functional expression of the mitochondrial pyruvate carrier. Science. 2012; 336:93-96. 
38. Gray LR, et al. Hepatic mitochondrial pyruvate carrier 1 is required for efficient regulation of gluconeogenesis and whole-body glucose homeostasis. Cell Metab. 2015; 22:669-681. [PubMed: 26344103]

39. Grenell A, et al. Loss of MPC1 reprograms retinal metabolism to impair visual function. Proc Natl Acad Sci U S A. 2019; 116:3530-3535. [PubMed: 30808746]

40. Wegrzyn J, et al. Function of mitochondrial Stat3 in cellular respiration. Science. 2009; 323:793797. [PubMed: 19131594]

41. Hamaidi I, et al. Sirt2 Inhibition Enhances Metabolic Fitness and Effector Functions of TumorReactive T Cells. Cell Metab. 2020; 32:420-436. [PubMed: 32768387]

42. Lim AR, Rathmell WK, Rathmell JC. The tumor microenvironment as a metabolic barrier to effector T cells and immunotherapy. Elife. 2020; 9:1-13.

43. Li X, et al. Navigating metabolic pathways to enhance antitumour immunity and immunotherapy. Nat Rev Clin Oncol. 2019; 16:425-441. [PubMed: 30914826]

44. Chapman NM, Boothby MR, Chi H. Metabolic coordination of T cell quiescence and activation. Nat Rev Immunol. 2020; 20:55-70. [PubMed: 31406325]

45. Qiao J, et al. Targeting Tumors with IL-10 Prevents Dendritic Cell-Mediated CD ${ }^{+}{ }^{+}$Cell Apoptosis. Cancer Cell. 2019; 35:901-915. e4 [PubMed: 31185213]

46. Naing A, et al. Pegilodecakin combined with pembrolizumab or nivolumab for patients with advanced solid tumours (IVY): a multicentre, multicohort, open-label, phase $1 \mathrm{~b}$ trial. Lancet Oncol. 2019; 20:1544-1555. [PubMed: 31563517]

47. Platt RJ, et al. CRISPR-Cas9 knockin mice for genome editing and cancer modeling. Cell. 2014; 159:440-455. [PubMed: 25263330]

48. Vanderperre B, et al. Embryonic Lethality of Mitochondrial Pyruvate Carrier 1 Deficient Mouse Can Be Rescued by a Ketogenic Diet. PLoS Genet. 2016; 12:1-20.

49. Cheng WC, et al. Uncoupling protein 2 reprograms the tumor microenvironment to support the anti-tumor immune cycle. Nat Immunol. 2019; 20:206-217. [PubMed: 30664764]

50. Tschumi BO, et al. CART cells are prone to Fas- and DR5-mediated cell death. J Immunother Cancer. 2018; 6:1-9. [PubMed: 29298730]

51. Guo Y, et al. Purification and characterization of human IL-10/Fc fusion protein expressed in Pichia pastoris. Protein Expr Purif. 2012; 83:152-156. [PubMed: 22484198]

52. Armour KL, Clark MR, Hadley AG, Williamson LM. Recombinant human IgG molecules lacking $\mathrm{Fc} \gamma$ receptor I binding and monocyte triggering activities. Eur J Immunol. 1999; 29:2613-2624. [PubMed: 10458776]

53. Steele AW, Nickerson PW, Steurer W, Steiger J, Strom TB. Administration of noncytolytic IL-10/Fc in murine models of lipopolysaccharide-induced septic shock and allogeneic islet transplantation. J Immunol. 1995; 154:5590-5600. [PubMed: 7730658]

54. Doench JG, et al. Optimized sgRNA design to maximize activity and minimize off-target effects of CRISPR-Cas9. Nat Biotechnol. 2016; 34:184-191. [PubMed: 26780180]

55. Ma L, et al. Enhanced CAR-T cell activity against solid tumors by vaccine boosting through the chimeric receptor. Science. 2019; 365:162-168. [PubMed: 31296767]

56. Michelet X, et al. Metabolic reprogramming of natural killer cells in obesity limits antitumor responses. Nat Immunol. 2018; 19:1330-1340. [PubMed: 30420624]

57. Picelli S, et al. Full-length RNA-seq from single cells using Smart-seq2. Nat Protoc. 2014; 9:171181. [PubMed: 24385147] 
a

- $P M E L+P B S$

- $P M E L+I L-10 / F C$
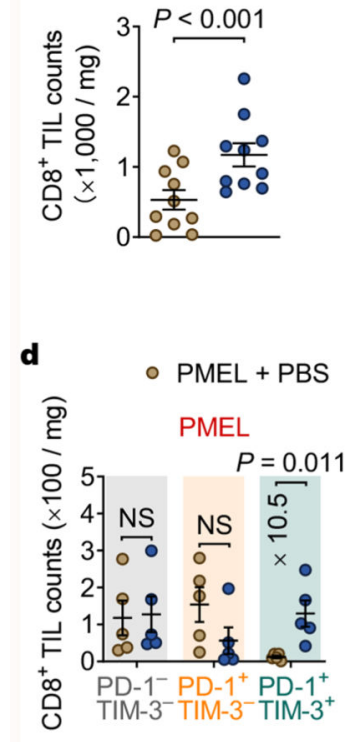

b

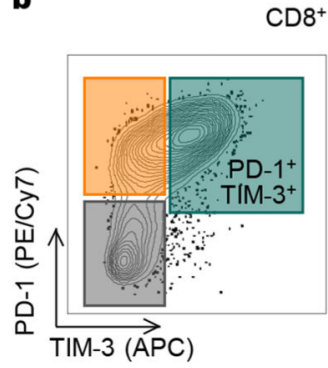

- PMEL + IL-10/FC

Endogenous

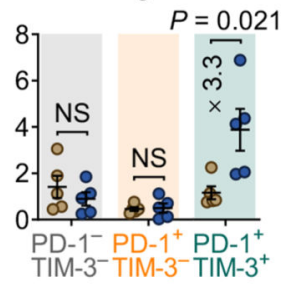

CD44+ TILs

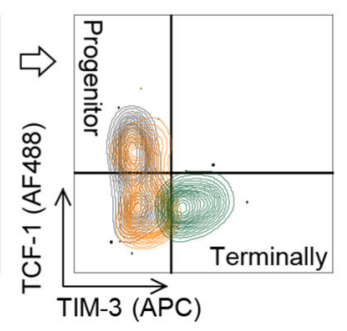

e $\quad$ PMEL + PBS

PMEL + IL-10/FC

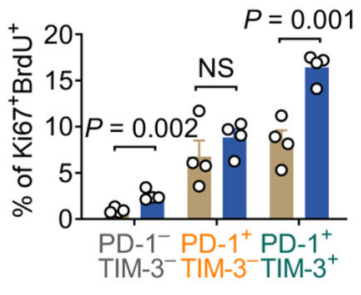

c
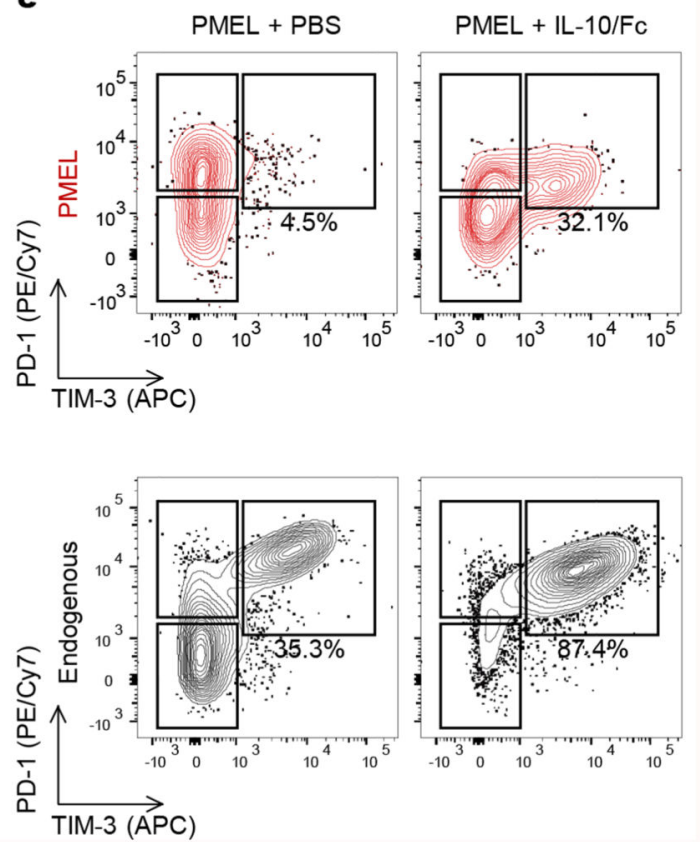

Fig. 1. IL-10/Fc expands terminally exhausted CD8 ${ }^{+}$TILs.

Thy $1.2^{+}$C57BL/6 mice were inoculated subcutaneously (s.c.) with B16F10 tumor cells $(1 \times$ $10^{6}$ ) and received intravenous (i.v.) adoptive transfer of activated Thy $1.1^{+}$PMEL CD $8^{+} \mathrm{T}$ cells $\left(5 \times 10^{6}\right)$ on day 6 followed by peritumoral (p.t.) administration of IL-10/Fc $(20 \mu \mathrm{g})$ or PBS control every other day until day 12 . On day 14 , mice were sacrificed and tumors were processed and analyzed by flow cytometry. Data are one representative of three or four independent experiments and $n=4$ independent animals unless otherwise noted. $\mathbf{a}$, Counts of $\mathrm{CD}^{+}$tumor infiltrating lymphocytes (TILs) in tumors. Shown are pooled data of two independent experiments ( $\mathrm{n}=10$ independent animals). $\mathbf{b}$, Gating strategy for terminally exhausted CD8 ${ }^{+}$TILs using surface markers PD-1 and TIM-3. c, Representative flow cytometry plots showing the frequencies of PD- $1^{+} \mathrm{TIM}-3^{+}$terminally exhausted $\mathrm{CD} 8^{+} \mathrm{T}$ cells among all $\mathrm{CD} 44^{+} \mathrm{CD} 8^{+}$TILs. d, Counts of three subpopulations among endogenous and PMEL CD8 ${ }^{+}$TILs ( $n=5$ independent animals). e, Frequencies of $\mathrm{Ki}^{+} 7^{+} \mathrm{BrdU}^{+} \mathrm{T}$ cells among each subpopulation of $\mathrm{CD} 8^{+}$TILs. All data represent the mean \pm s.e.m. and are analyzed by two-sided Student's $t$-test; NS, not significant $(P>0.05)$. 
a

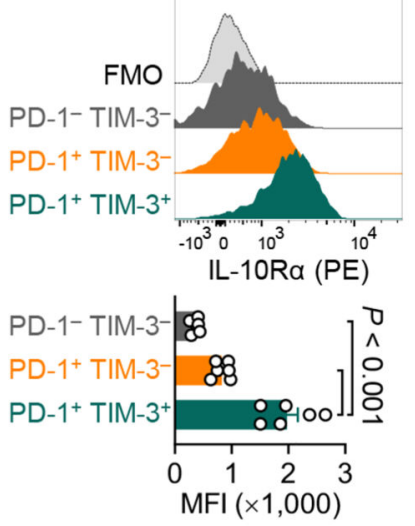

PMEL + PBS

PMEL + IL-10/Fc

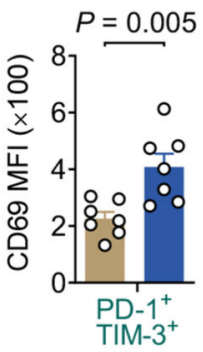

b

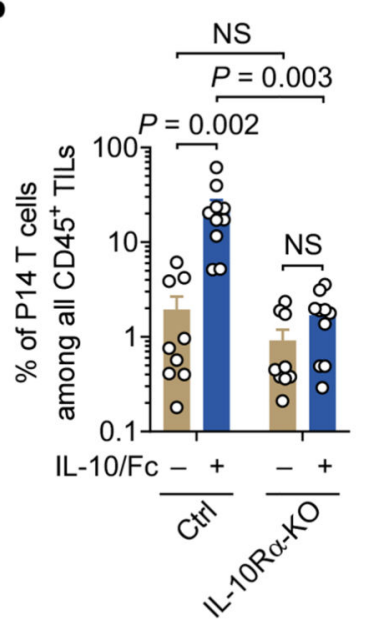

c

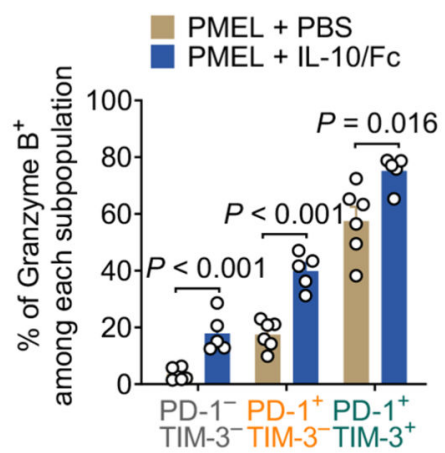

d

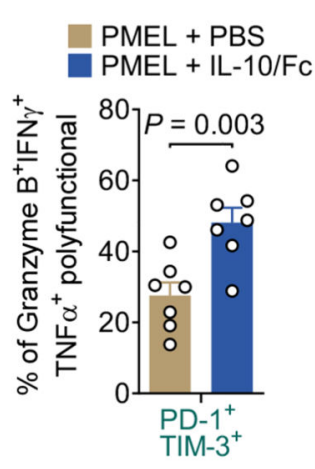

f
PBS
IL-10/Fc PD-1+TIM- $3^{+}$endogenous CD8+ TILs

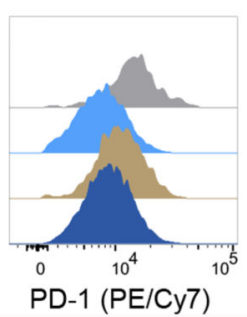

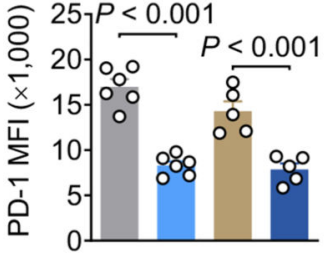

$\square$ PMEL + PBS $\quad$ PMEL + IL-10/Fc PD-1+TIM-3+ PMEL CD8+ TILS

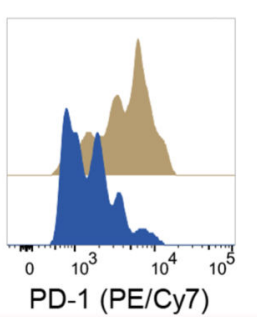

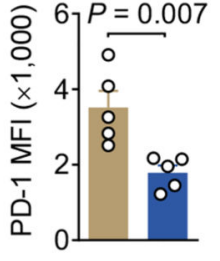

Fig. 2. IL-10/Fc expands CD8 ${ }^{+} T$ cells through IL-10R and enhances their effector function. The experimental setting was the same as descried in Fig. 1. Data are one representative of three or four independent experiments. a, Representative flow cytometry plots (upper) and mean fluorescence intensity (MFI, bottom) showing IL-10 receptor-a (IL-10Ra) expression on three subpopulations of $\mathrm{CD} 8^{+}$TILs ( $\mathrm{n}=6$ independent animals). FMO, fluorescence minus one. b, CD45.2 $2^{+}$Rosa26-Cas9 knock in (Cas9-KI) mice were inoculated s.c. with B16-gp33 tumor cells $\left(2 \times 10^{5}\right)$ and received an i.v. adoptive co-transfer of activated CD45. $1^{+} \mathrm{CD} 45.2^{+} \mathrm{P} 14 \mathrm{CD} 8^{+} \mathrm{T}$ cells $\left(\mathrm{Ctrl}, 2 \times 10^{6}\right)$ and activated CD45. $\mathrm{IL}-10 \mathrm{Ra}-\mathrm{knock}$ out (IL-10Ra-KO) P14 CD8 ${ }^{+}$T cells $\left(2 \times 10^{6}\right)$ on day 10 followed by p.t. administration of $\mathrm{IL}-10 / \mathrm{Fc}(20 \mu \mathrm{g})$ or PBS control every other day until day 16 . On day 18 , mice were sacrificed and tumors were processed and analyzed by flow cytometry. Data are pooled from two independent experiments ( $\mathrm{n}=9$ independent animals). Shown are frequencies of $\mathrm{Ctrl}$ P14 T cells and IL-10Ra-KO P14 T cells among all CD45+ TILs. c, Frequencies of granzyme $\mathrm{B}^{+} \mathrm{CD} 8^{+} \mathrm{T}$ cells among each subpopulation of CD8 $8^{+}$TILs $(\mathrm{n}=5$ independent animals). d, Frequencies of granzyme $\mathrm{B}^{+} \mathrm{IFN} \gamma^{+} \mathrm{TNFa}^{+}$polyfunctional cells among PD- $1^{+}$TIM- $3^{+}$CD8 ${ }^{+}$TILs ( $n=7$ independent animals). e, MFI of CD69 expressed on PD $-1^{+}$TIM $-3^{+} \mathrm{CD}^{+}$TILs ( $\mathrm{n}=5$ independent animals). $\mathbf{f}$, Representative flow cytometry histograms showing PD-1 expression level and MFI of PD-1 in endogenous and PMEL PD- $1^{+}$TIM- $3^{+} \mathrm{CD} 8^{+}$TILs ( $\mathrm{n}=5$ independent animals). All data represent the mean \pm s.e.m. and are analyzed by one-way ANOVA and Tukey's test or two-sided Student's $t$-test; NS, not significant $(P>0.05)$. 
a

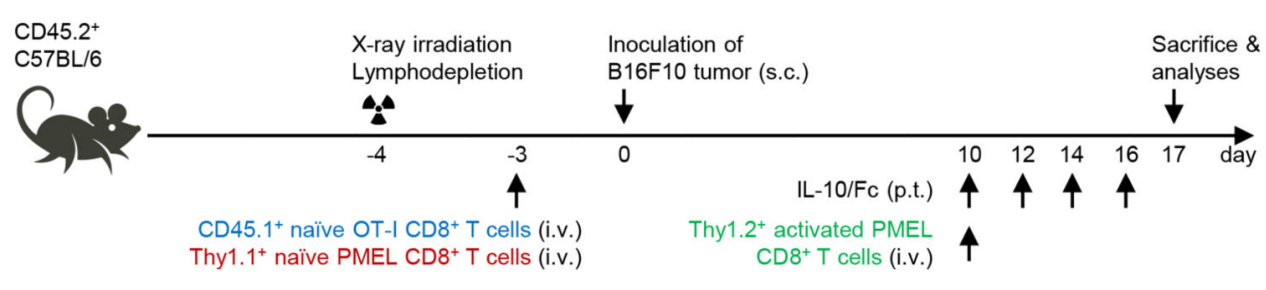

b
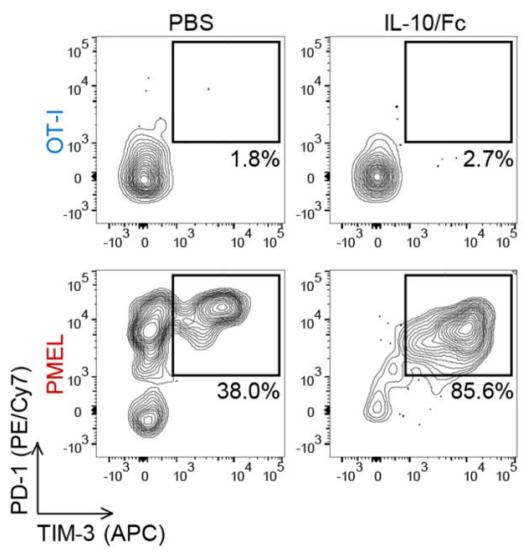

e

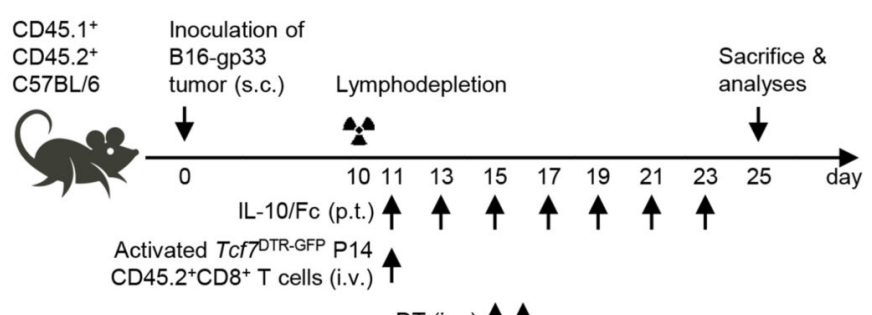

DT (i.p.) $4 \uparrow$

$\mathbf{g}$

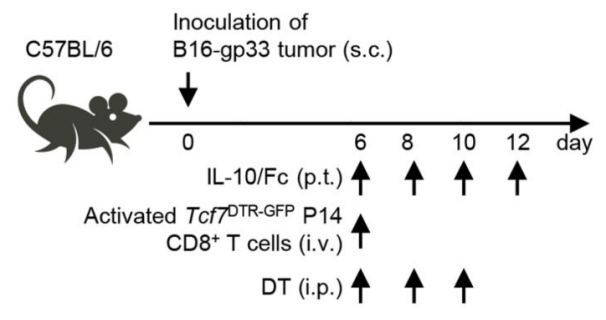

h
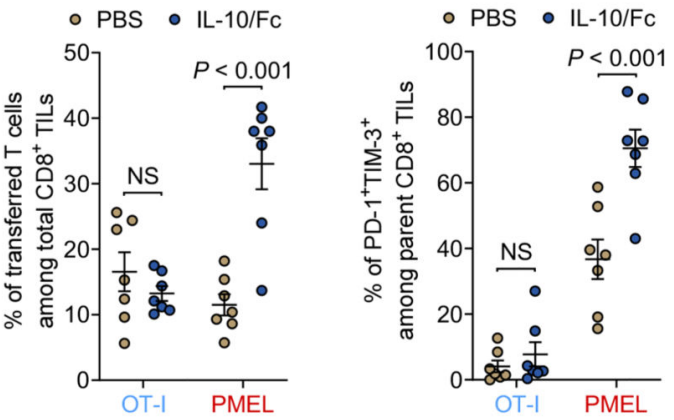

Fig. 3. IL-10/Fc expands antigen-specific terminally exhausted $\mathrm{CD8}^{+} \mathrm{T}$ cells in a progenitor exhausted cell-independent manner.

a-d, Thy $1.2^{+}$C57BL/6 mice were sublethally lymphodepleted and received adoptive cotransfer of Thy $1.1^{+}$naïve PMEL and CD45.1 ${ }^{+}$naïve OT-I CD ${ }^{+}$T cells. The mice were then inoculated with B16F10 tumor cells. On day 10, the mice were treated with adoptive transfer of activated Thy 1.2 ${ }^{+}$PMEL CD8 ${ }^{+} \mathrm{T}$ cells followed by administration of IL-10/Fc or PBS control. On day 17, mice were sacrificed for flow cytometry analyses of TILs ( $\mathrm{n}=7$ independent animals). a, Experimental timeline. b, Representative flow cytometry plots 
showing the frequencies of PD- $1^{+}$TIM- $3^{+}$subpopulation among OT-I or PMEL (Thy $1.1^{+}$) CD8 ${ }^{+}$TILs. c, Frequencies of transferred OT-I or PMEL (Thy $1.1^{+}$) cells among total CD8 ${ }^{+}$ TILs. d, Frequencies of PD- $1^{+}$TIM- $3^{+}$subpopulation among total transferred OT-I or PMEL (Thy $1.1^{+}$) CD8 ${ }^{+}$TILs. e,f, CD45.1 ${ }^{+}$CD $45.2^{+}$C57BL/6 mice were inoculated with B16-gp33 tumor cells and sublethally lymphodepleted by total body irradiation. Mice received i.v. adoptive transfer of activated CD $45.2^{+} T c f 7^{\text {DTR-GFP }} \mathrm{P} 14 \mathrm{CD} 8^{+} \mathrm{T}$ cells followed by administration of IL-10/Fc or PBS control. To deplete TCF- $1^{+} \mathrm{P} 14 \mathrm{CD} 8^{+} \mathrm{T}$ cells, diphtheria toxin (DT) was given intraperitoneally (i.p.). On day 25 , all mice were sacrificed and tumors were processed and analyzed by flow cytometry ( $\mathrm{n}=5$ independent animals). $\mathbf{e}$,

Experimental timeline. f, Frequencies of terminally exhausted $\left(T c f 7^{\left.-\mathrm{P}-\mathrm{PD}-1^{+} \mathrm{TIM}-3^{+}\right)} \mathrm{P} 14\right.$ $\mathrm{CD} 8^{+} \mathrm{T}$ cells among all CD8 ${ }^{+}$TILs. g,h, C57BL/6 mice were inoculated with B16-gp33 tumor cells and received adoptive transfer of activated $T c f 7^{\text {DTR-GFP P14 }} \mathrm{CD} 8^{+} \mathrm{T}$ cells followed by p.t. administration of IL-10/Fc or PBS control. DT was given i.p. to deplete TCF-1 $1^{+}$P14 CD8 ${ }^{+}$T cells. g, Experimental timeline. $\mathbf{h}$, Average tumor growth curves of each treatment group ( $n=5$ independent animals). Shown in parentheses is the number of long-term surviving mice among the total number of mice in the group. All data represent the mean \pm s.e.m. and are analyzed by two-sided Student's $t$-test $(\mathbf{c}, \mathbf{d})$ or one-way ANOVA and Tukey's test (f) or two-way ANOVA (h); NS, not significant $(P>0.05)$. 
a

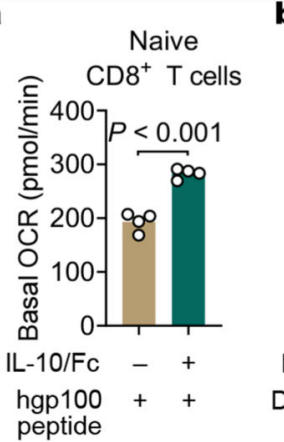

b

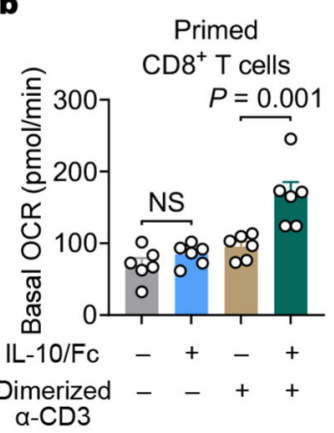

c

$\theta+$ PBS $\quad \theta+$ B16F10 + PBS

$\ominus+\mathrm{IL}-10 / \mathrm{FC} \bullet+\mathrm{B} 16 \mathrm{~F} 10+\mathrm{IL}-10 / \mathrm{Fc}$

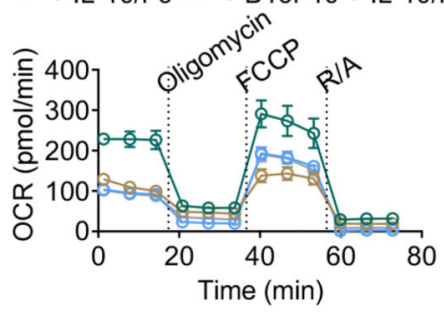

d

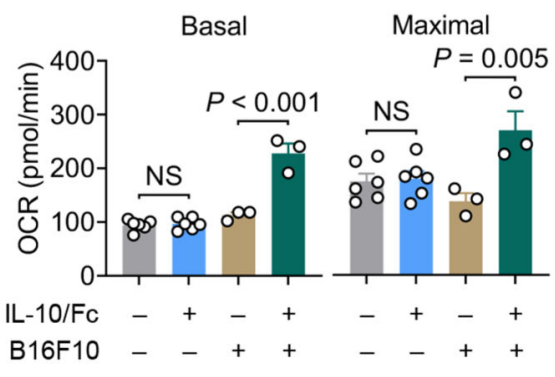

e

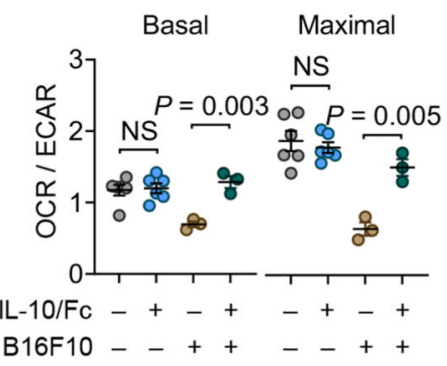

$\mathbf{f}$

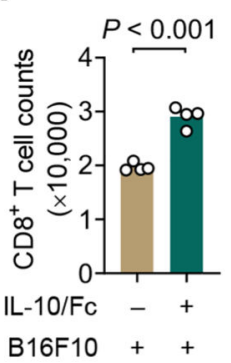

g

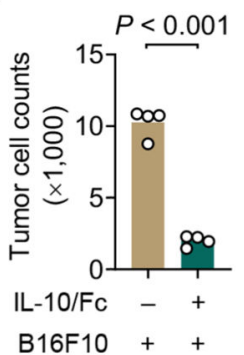

h

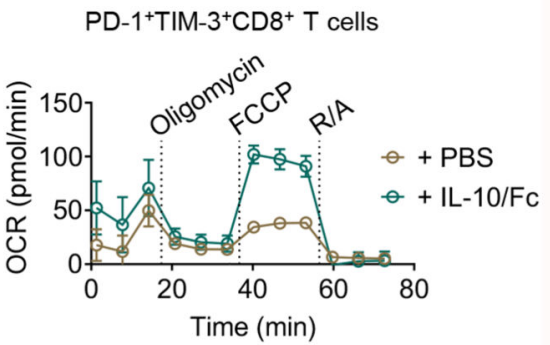

i

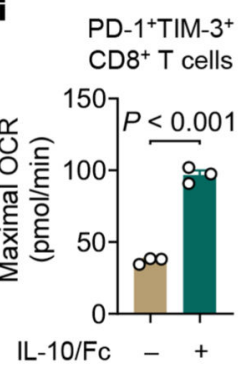

j

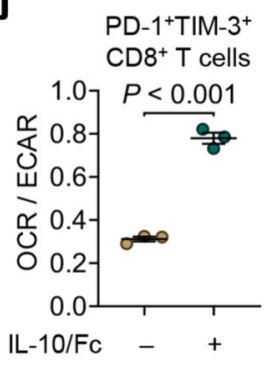

$\mathbf{k}$

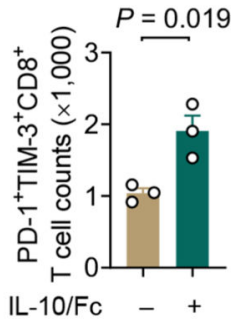

I

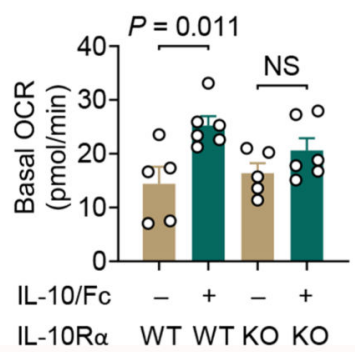

m

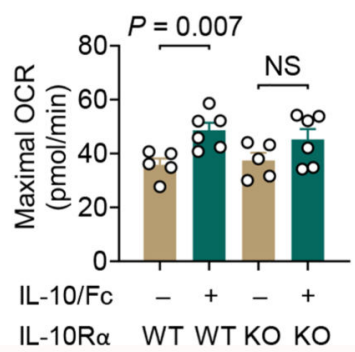

Fig. 4. IL-10/Fc reprograms $\mathrm{CD8}^{+} \mathrm{T}$ cell metabolism by promoting OXPHOS.

a, Basal oxygen consumption rate (OCR) of naïve PMEL CD8 ${ }^{+} \mathrm{T}$ cells from splenocytes activated with hgp100 peptide in the presence or absence of IL-10/Fc for 2 days. Data are one representative of three independent experiments ( $n=4$ independent samples). b. Basal OCR of primed PMEL CD8 ${ }^{+} \mathrm{T}$ cells in resting phase (day 7) restimulated by dimerized antiCD3 (a-CD3) antibody in the presence or absence of IL-10/Fc for 1 day. Data are one representative of three independent experiments ( $n=6$ independent samples). c-g, Primed PMEL $\mathrm{CD} 8^{+} \mathrm{T}$ cells in the resting phase were co-cultured with $\mathrm{B} 16 \mathrm{~F} 10$ tumor cells at a ratio of 1 to 1 in the presence or absence of IL-10/Fc for 2 days. CD8 ${ }^{+} \mathrm{T}$ cells were isolated for Seahorse assay and flow cytometry analyses. Data are one representative of at least three independent experiments ( $\mathrm{n}=3$ independent samples). c, Real-time analysis of OCR. d, Average basal and maximal OCR. e, Ratios of OCR to extracellular acidification rate (ECAR). $\mathbf{f}, \mathbf{g}$, Counts of $\mathrm{CD} 8^{+} \mathrm{T}$ cells $(\mathbf{f})$ and tumor cells $(\mathbf{g})$ in the co-culture assay. $\mathbf{h}-\mathbf{k}$, PMEL PD $-1^{+} \mathrm{TIM}-3^{+} \mathrm{CD} 8^{+} \mathrm{T}$ cells were sorted from in vitro culture with restimulation by dimerized a-CD3 antibody for 1 day in the presence or absence of IL-10/Fc $(n=3$ independent samples). h, Real-time analysis of OCR. i, Average maximal OCR. $\mathbf{j}$, Ratios of 
maximal OCR to ECAR. $\mathbf{k}$, Sorted PMEL PD- $1^{+} \mathrm{TIM}-3^{+} \mathrm{CD} 8^{+} \mathrm{T}$ cells were cocultured with B16F10 cells at the ratio of 1:1 in the presence or absence of IL-10/Fc for 2 days. Shown are average PD- $1^{+} \mathrm{TIM}-3^{+} \mathrm{CD} 8^{+} \mathrm{T}$ cell counts. Data are one representative of two independent experiments ( $\mathrm{n}=3$ independent samples). I-m, Control P14 CD8 ${ }^{+} \mathrm{T}$ cells with wild type IL-10Ra (WT) or IL-10Ra-KO P14 CD8 ${ }^{+} \mathrm{T}$ cells (KO) were restimulated by dimerized $\mathrm{a}-$ CD3 antibody in the presence or absence of IL-10/Fc and cultured for 2 days. Shown are average basal (I) and maximal (m) OCR. Data are one representative of two independent experiments ( $n=5$ independent samples). All data represent the mean \pm s.e.m. and are analyzed by one-way ANOVA and Tukey's test or two-sided Student's $t$-test; NS, not significant $(P>0.05)$. 


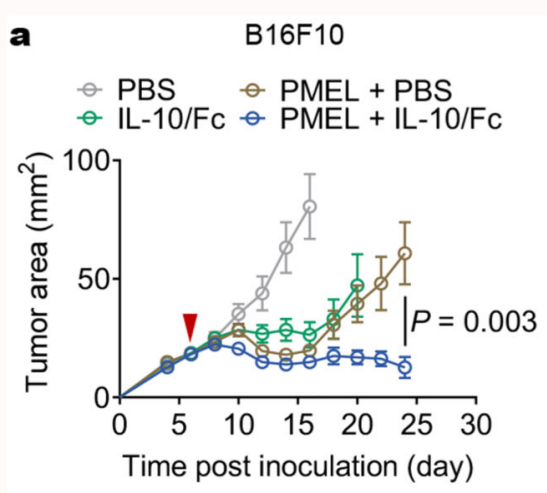

b
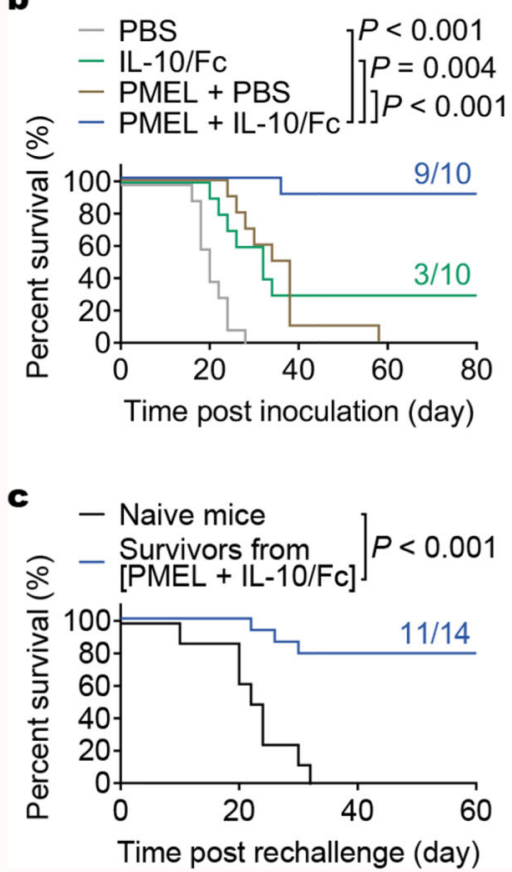

d

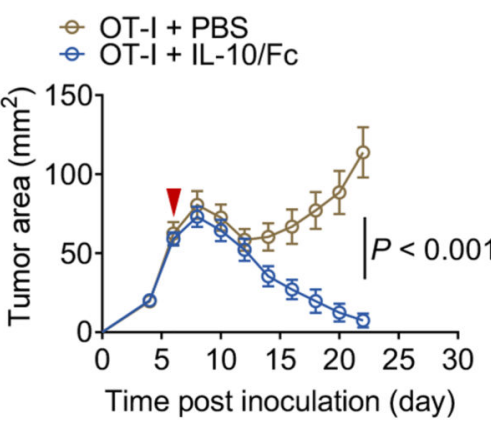

e

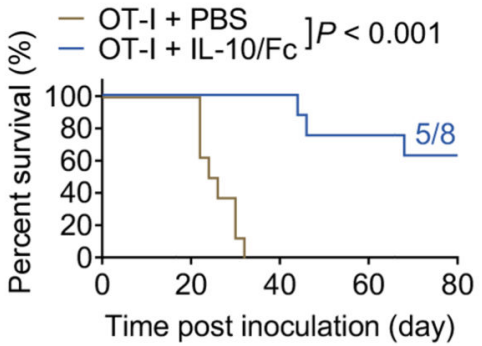

$\mathbf{f}$

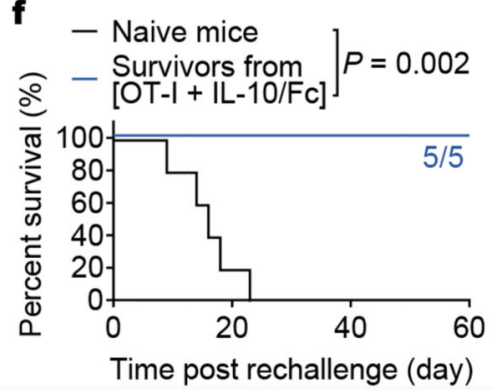

g

MC38-HER2

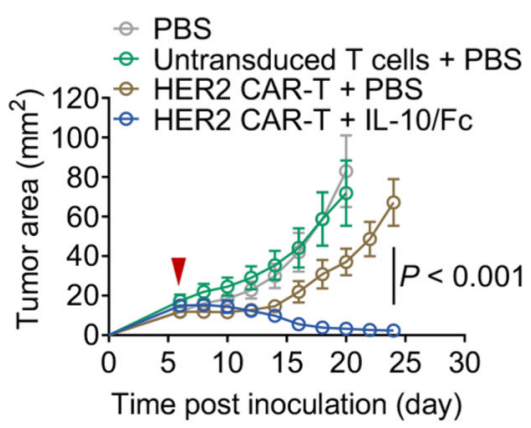

$\mathbf{h}$

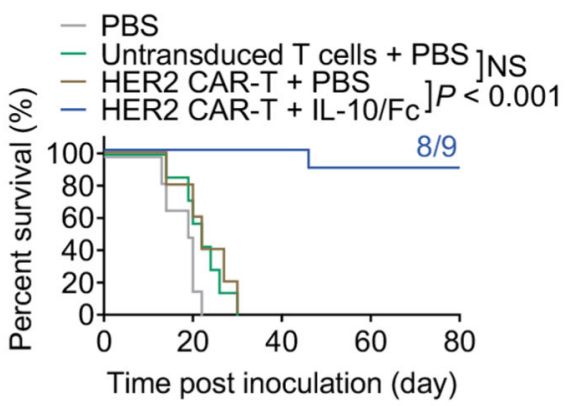

i

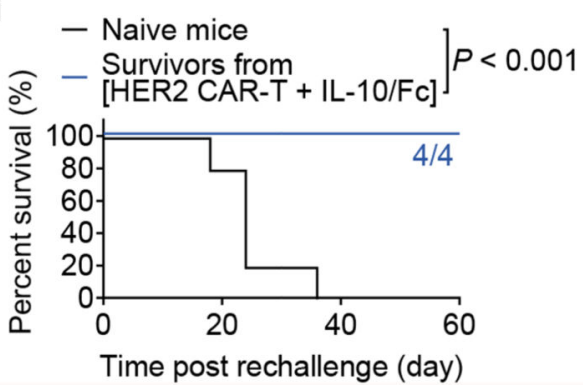

Fig. 5. IL-10/Fc potentiates ACT therapies to eradicate established tumors in multiple mouse models with durable protection.

Thy $1.2^{+}$C57BL/6 mice were inoculated s.c. with B16F10 melanoma cells $\left(5 \times 10^{5}\right)$,

YUMM1.7-OVA melanoma cells $\left(1 \times 10^{6}\right)$, or MC38-HER2 colon adenocarcinoma cells $(1$ $\left.\times 10^{6}\right)$ and received i.v. adoptive cell transfers of activated Thy $1.1^{+}$PMEL CD8 ${ }^{+} \mathrm{T}$ cells $(5 \times$ $\left.10^{6}\right)$, OT-I CD $8^{+} \mathrm{T}$ cells $\left(5 \times 10^{6}\right)$, or HER2-CAR T cells $\left(5 \times 10^{6}\right)$, respectively on day 6 , followed by p.t. administration of IL-10/Fc $(20 \mu \mathrm{g})$ or PBS control every other day until day 20. Mice receiving injections of PBS control or IL-10/Fc $(20 \mu \mathrm{g} \times 8)$ only served as controls in the B16F10 model. Mice receiving injections of PBS control or untransduced T cells served as controls in the MC38-HER2 model. Shown are average tumor growth curves $(\mathbf{a}, \mathbf{d}, \mathbf{j})$ and survival curves $(\mathbf{b}, \mathbf{e}, \mathbf{h})$ of each treatment group in different tumor models. Red arrows indicate the start of treatment. Shown are numbers of long-term surviving mice among the total number of mice in the group $(\mathbf{b}, \mathbf{e}, \mathbf{h})$. Survivors from treatment groups of combination of adoptive $\mathrm{T}$ cell transfer (ACT) therapies and IL-10/Fc in three different models were re-challenged s.c. by B16F10 $\left(1 \times 10^{5}\right)$, YUMM1.7-OVA $\left(5 \times 10^{5}\right)$, or MC38HER $2\left(1 \times 10^{6}\right)$ cells, respectively on day 90 post primary inoculation. Naïve WT mice $(\mathrm{n}=$ 
5) were inoculated with the same number of tumor cells as controls. Shown are survival curves (c,f,ii) and numbers of long-term surviving mice against the re-challenges. a-c, Therapy study with B16F10 model. Shown are pooled data of two independent experiments ( $\mathrm{n}=10$ independent animals). d-f, Therapy study with YUMM1.7-OVA model. Shown is one representative of three independent experiments ( $\mathrm{n}=8$ independent animals). $\mathbf{g}$-i, Therapy study with MC38-HER2 model. Shown are pooled data of two independent experiments ( $n=6$ independent animals). Data represent the mean \pm s.e.m. and are analyzed by two-sided Student's $t$-test for tumor growth data and Log-rank test for survival curves; NS, not significant $(P>0.05)$. 


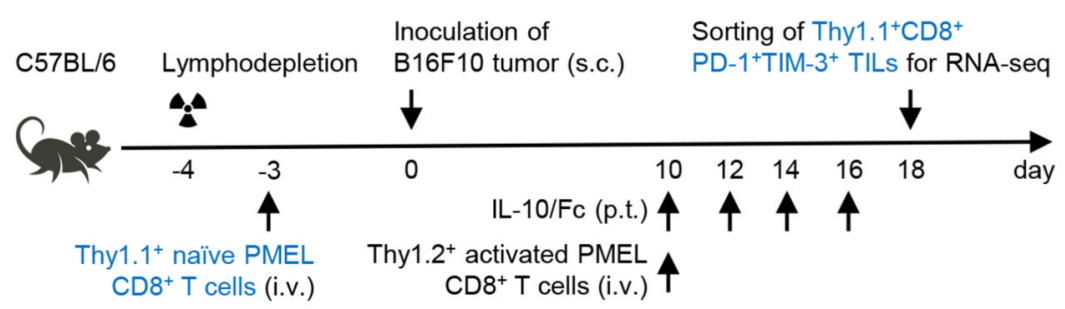

b

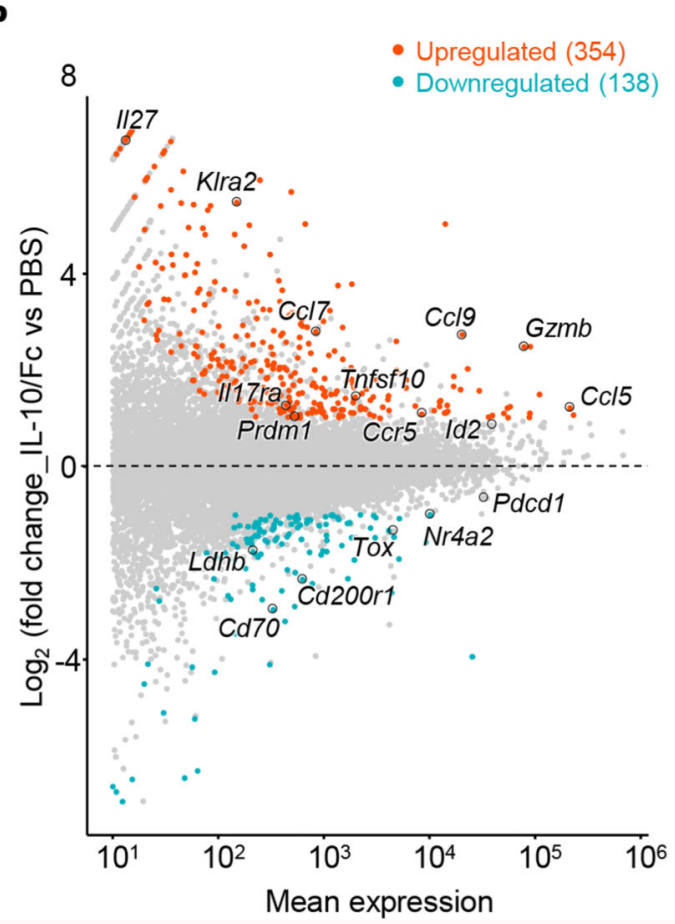

c

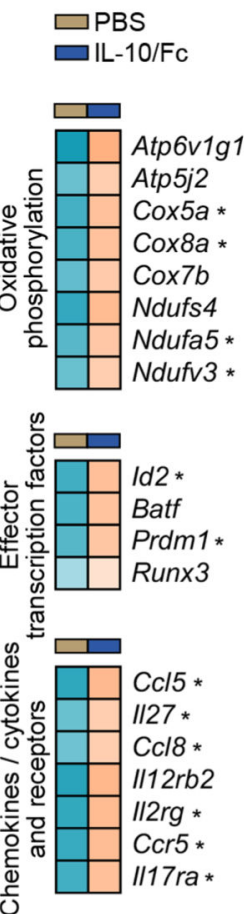

d
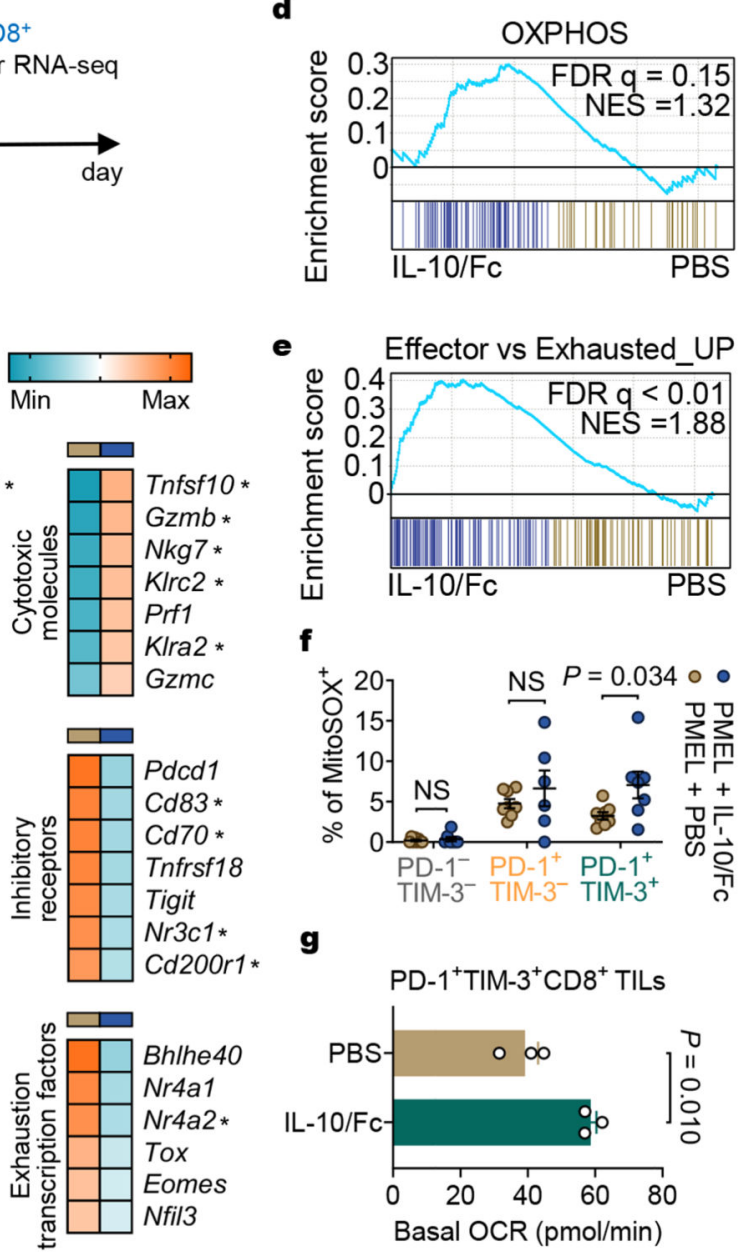

Fig. 6. IL-10/Fc upregulates OXPHOS and expression of genes encoding effector function of terminally exhausted $\mathrm{CD8}^{+}$TILs.

a-e, Thy $1.2^{+}$C57BL/6 mice were sublethally lymphodepleted and received adoptive transfer of Thy $1.1^{+}$naïve PMEL CD8 ${ }^{+}$T cells. Mice were inoculated with B16F10 tumor cells and were treated with adoptive transfer of activated Thy $1.2^{+}$PMEL CD ${ }^{+} \mathrm{T}$ cells followed by administration of IL-10/Fc or PBS control. On day 18, tumor infiltrating Thy $1.1^{+} \mathrm{PD}-1^{+} \mathrm{TIM}-3^{+} \mathrm{CD} 8^{+} \mathrm{T}$ cells were sorted for profiling gene expression with RNA sequencing ( $\mathrm{n}=2$ for PBS group, $\mathrm{n}=4$ for IL-10/Fc group). a, Experimental timeline. b, Mean average plot of the RNA-seq dataset [graph shows fold change in expression $\left(\log _{2}\right.$ (IL-10-Fc/PBS)) versus mean expression of genes ( $\log _{10}$ (base mean)) with mean expression? 10, and $\left.\left|\log _{2}(\mathrm{IL}-10-\mathrm{Fc} / \mathrm{PBS})\right| \leq 7\right]$. Significantly upregulated or downregulated genes are shown in orange or blue, respectively (false discovery rate (FDR)-adjusted $P$ value $<0.05$ and $\mid \log _{2}$ (fold change) $\mid>1$ ). Two-tailed Wald statistic was used; Adjustment for multiple comparison (padj): Benjamini-Hochberg (BH) adjusted $P$ values. c, Heat map illustrating the average transcript expression of the indicated genes. Rows represent averaged Z-scores. Asterisks represent transcripts with significant differential expression by DESeq2 (FDR <0.05). d,e, Enrichment of gene signatures from MSigDB by gene-set permutation test. Enrichment score is calculated based on a weighted Kolmogorov-Smirnov-like statistic 
test. Adjustment for multiple comparison (FDR q value): $\mathrm{BH}$ adjusted $P$ values. Gene set enrichment analyses of OXPHOS (d) and effector function (e) were performed to compare PD- $1^{+}$TIM- $3^{+} \mathrm{CD} 8^{+}$TILs treated with IL-10/Fc versus PBS. f, The experimental setting was the same as that shown in Fig. 1. Shown are frequencies of MitoSOX ${ }^{+} \mathrm{CD}^{+} \mathrm{T}$ cells among each subpopulation of $\mathrm{CD}^{+}$TILs. Data are representative of two independent experiments ( $\mathrm{n}=7$ independent animals). $\mathrm{g}$, Thy $1.2^{+}$C57BL/6 mice bearing YUMM1.7-OVA tumors received adoptive transfer of activated $\mathrm{CD} 45.1^{+}$OT-I CD $8^{+} \mathrm{T}$ cells and followed by administration of IL-10/Fc or PBS control every other day until day 20. On day 22, CD8 ${ }^{+}$ TILs from pooled samples were enriched and PD- $1^{+}$TIM- $3^{+} \mathrm{CD} 8^{+}$TILs were sorted. Shown are average basal OCR. Data are one representative of two independent experiments $(n=3$ independent samples). All data represent the mean \pm s.e.m. and are analyzed by two-sided Student's $t$-test; NS, not significant $(P>0.05)$. 
a

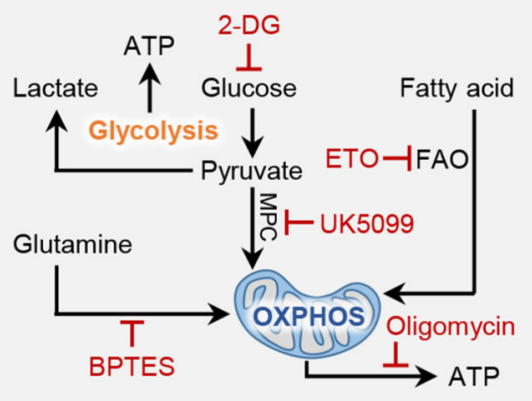

b

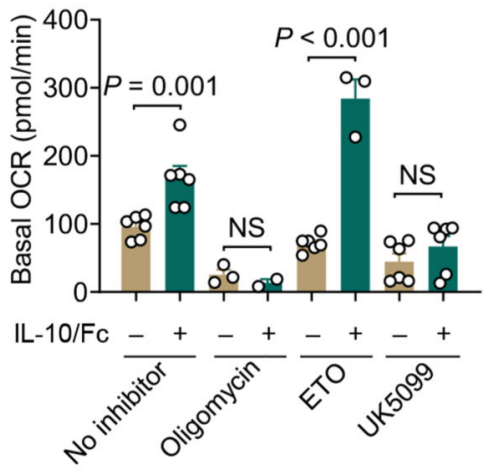

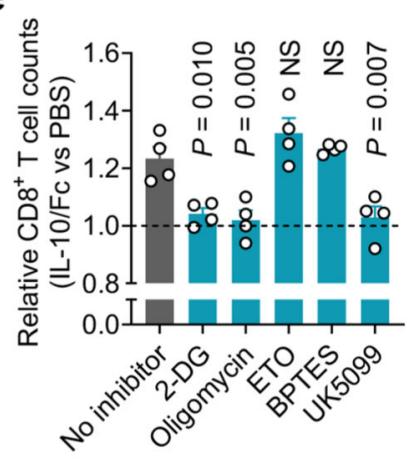

d

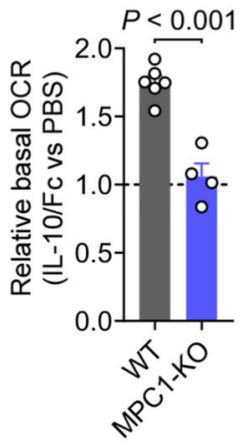

i

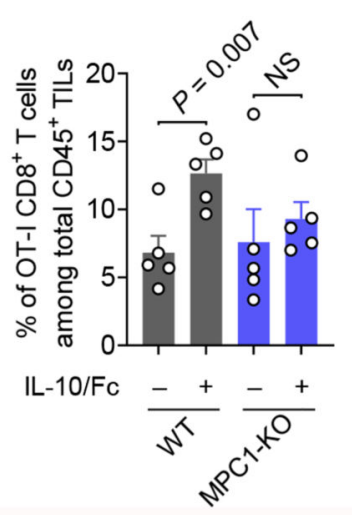

$\mathbf{g}$

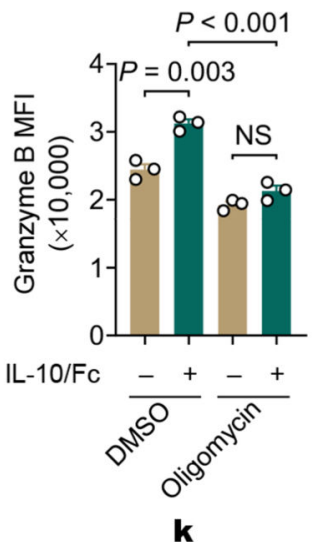

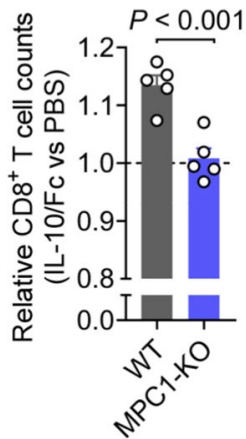

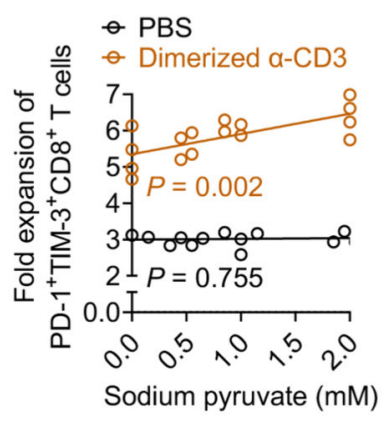

$\mathbf{h}$

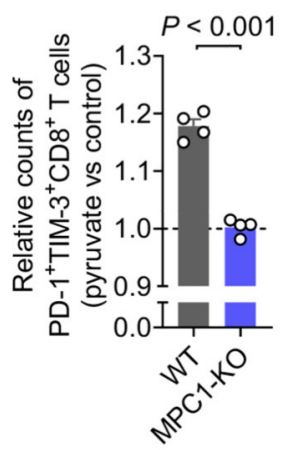

Fig. 7. IL-10/Fe promotes T cell OXPHOS and anti-tumor immunity in a MPC-dependent manner.

a-c, Resting PMEL CD8 ${ }^{+} \mathrm{T}$ cells were restimulated by dimerized a-CD3 antibody in the presence of indicated inhibitors for 2 days with or without IL-10/Fc. Data are one representative of three independent experiments ( $n=4$ independent samples). a, Related metabolism pathways and inhibitors used. b, Basal OCR of PMEL CD $8^{+} \mathrm{T}$ cells. $\mathbf{c}$, Fold change of $\mathrm{CD}^{+} \mathrm{T}$ cell counts. d,e, Resting wild type (WT) or mitochondrial pyruvate carrier 1 knock out (MPC1-KO) OT-I CD8 ${ }^{+} \mathrm{T}$ cells were restimulated by dimerized $\mathrm{a}-\mathrm{CD} 3$ antibody in the presence or absence of IL-10/Fc for 2 days. Shown are relative basal OCR of $\mathrm{CD}^{+} \mathrm{T}$ cell $(\mathbf{d})$ and relative $\mathrm{CD} 8^{+} \mathrm{T}$ cell counts $(\mathbf{e})(\mathrm{n}=5$ independent samples). $\mathbf{f}$, Resting 
PMEL CD8 ${ }^{+} \mathrm{T}$ cells were restimulated similarly as that in a-c in the presence or absence of oligomycin for 2 days. MFI of intracellular granzyme B production was measured $(n=3$ independent samples). $\mathbf{g}, \mathbf{h}$, Resting PMEL $\mathrm{CD}^{+} \mathrm{T}$ cells were cultured in low-glucose medium with different concentrations of sodium pyruvate for 2 days. $\mathbf{g}$, Shown is fold expansion of PD- $1^{+}$TIM- $3^{+} \mathrm{CD} 8^{+} \mathrm{T}$ cells. $\mathbf{h}$, Resting WT and MPC1-KO OT-I CD8 ${ }^{+} \mathrm{T}$ cells were cultured similarly as that in $\mathbf{g}$. Shown is fold expansion of PD- $1^{+} \mathrm{TIM}-3^{+} \mathrm{CD} 8^{+} \mathrm{T}$ cells with sodium pyruvate $(3 \mathrm{mM})$ versus control. $\mathbf{i}-\mathbf{j}$, CD $45.1^{+} \mathrm{CD} 45.2^{+} \mathrm{C} 57 \mathrm{BL} / 6$ mice bearing B16F10-OVA tumors received adoptive transfer of activated CD45.1 ${ }^{+} \mathrm{WT}$ or CD45.2 $2^{+}$ MPC1-KO OT-I CD8 ${ }^{+}$T cells followed by administration of IL-10/Fc or PBS control every other day until day 13 ( $n=5$ independent animals). Frequencies of transferred OT-I CD8 ${ }^{+} \mathrm{T}$ cells among total CD $45^{+}$TILs (i) and relative counts of PD- $1^{+} \mathrm{TIM}-3^{+} \mathrm{CD} 8^{+} \mathrm{TILs}(\mathbf{j})$ on day 15. k, C57BL/6 mice bearing YUMM1.7-OVA tumors were sublethally lymphodepleted and received adoptive transfer of activated WT or MPC1-KO OT-I CD8 ${ }^{+} \mathrm{T}$ cells on day 10 followed by administration of IL-10/Fc or PBS control every other day until day 24 . Shown are average tumor growth curves of each treatment group $(n=4$ independent animals). All data represent the mean \pm s.e.m. and are analyzed by twosided Student's $t$-test or one-way ANOVA with Tukey's test or two-way ANOVA (k). NS, not significant $(P>0.05)$. 